\title{
Gains from Others' Losses: Technology Trajectories and the Global Division of Firms
}

\author{
Chia-Hsuan Yang ${ }^{1}$, Rebecca Nugent ${ }^{2}$, Erica R.H. Fuchs ${ }^{1 *}$ \\ ${ }^{1}$ Department of Engineering and Public Policy, Carnegie Mellon University, Pittsburgh Pennsylvania, U.S.A \\ ${ }^{2}$ Department of Statistics, Carnegie Mellon University, Pittsburgh Pennsylvania, U.S.A \\ * Correspondence to: Erica R.H. Fuchs, Department of Engineering and Public Policy, Carnegie Mellon University, 5000 Forbes Avenue, \\ Baker Hall 131E, Pittsburgh, PA 15213, United States Tel.: +1 412268 1877; fax: +1 412268 3757. E-mail address: erhf@andrew.cmu.edu.
}

This paper offers new insights into the role of firms versus individuals in driving technology directions, and the extent to which human capital may be lost during industrial shifts. We explore in particular whether (1) due to different offshore production economics, firms who move manufacturing offshore slow U.S.-based R\&D activities in an emerging technology and (2) the inventors originally within these offshoring firms, leave, and continue innovating in the emerging technology at different institutions. We focus on the 28 leading U.S. optoelectronic component manufactures for telecommunications and the inventors who patent at these firms. We triangulate hand-classified USPTO patents, SEC filings, inventor resumes, survey data, and select interviews of key inventors. We find that, in the case of U.S. optoelectronic component manufacturers for telecommunications, offshoring is associated with a decrease in innovation in the emerging technology, but an increase in all other types of patenting. While the majority of inventors depart to firms outside the industry and stop work in the emerging technology, an important minority of emerging technology inventors at the offshoring firms depart to a single onshore firm in the same industry (which gains from others' losses and subsequently dominates this space). Our results suggest a strong role for firms and firm strategy in driving innovation directions, and the corresponding opportunities faced by individuals.

Key words: offshoring; innovation; human capital; product life cycle; manufacturing; location of knowledge

\section{Introduction}

In the technology strategy literature there exists a tension regarding the respective roles of firms versus individuals in driving technology directions and the extent to which each holds the knowledge stocks for driving those directions. On the one hand, research has pointed out the importance of firm strategy in identifying technology trajectories and driving innovation (Abernathy and Clark, 1985;

Christensen, 1997; Henderson and Clark, 1990). On the other hand, a significant literature has viewed the individual as the source of knowledge capital, emphasizing the role of scientist and engineer mobility in disseminating knowledge (Agarwal et al., 2004; Almeida and Kogut, 1999; Klepper and Sleeper, 2005; Rosenkopf and Almeida, 2003) and the lengths to which inventors will go to persist in their research directions (Furman et al., 2012; Garud and Rappa, 1995; Klepper and Thompson, 2010).

These tensions on the interaction between firm and individual strategies in driving technology 
directions play themselves out in the debates on offshoring. Here, research has suggested that if firms move manufacturing overseas to developing nations, these firms may lose incentives to produce the most advanced technologies (Fuchs and Kirchain, 2010) and supporting industrial commons (Pisano and Shih, 2009) and R\&D (Fifarek et al., 2008) may soon follow.

Leveraging a case of extensive offshoring by U.S. optoelectronic component manufacturers for telecommunications, this research seeks to contribute to these larger debates. We first seek to understand whether, due to different offshore production economics, firms that move manufacturing offshore slow U.S.-based R\&D activities in the emerging technology, as past research by Fuchs et al would suggest (Fuchs and Kirchain, 2010). We then explore the implications of the firm's offshoring decisions for inventor innovation trajectories (and thus the human capital originally built within those firms). In particular, we seek to understand whether inventors originally employed at these firms continue innovating in the emerging technology at different institutions.

This paper leverages an extensive new dataset on the optoelectronics industry to unpack the relationship between offshoring of manufacturing to low-wage countries and innovation directions back in the United States. We focus our study on the 28 leading U.S. optoelectronic component manufacturers for telecommunications and the inventors who patent at these firms. Leveraging seven different sources of industry data, we hand-construct a dataset of all U.S. -owned optoelectronic component manufactures for telecommunications. We then triangulate hand-classified USPTO patents, SEC filings, phone-collected firm survey data, inventor resumes, and select interviews with key inventors.

We find that the majority of individuals change research directions in association with their choice of institutions (in this case, to which firms, they go). Meanwhile, the firms and their associated strategies (both in offshoring and in hiring) dominate our story on innovation. Specifically, we find that offshoring is associated with a decrease in firm innovation in the emerging technology. The majority of inventors depart to firms outside the industry and stop work in the emerging technology. However, an important minority of inventors from across the offshoring firms move to a single onshore firm in the same industry, which "gains from others' losses" and subsequently dominates emerging technology innovation in the industry. Interestingly, the inventors that go to the firm that stays onshore and dominates in the emerging technology largely are not those with existing knowledge capital therein. The constraint is not fear of noncompete enforcement or patent litigation, rather inventors who were leaders in the emerging technology prior to offshoring choosing for a variety of reasons to not pursue jobs at the onshore firm.

These results contribute to current debates on the benefits of domestic manufacturing and the relationship between manufacturing and innovation. Specifically, we find that what type of manufacturing facility is moved overseas to a developing nation is critical to determining whether - as traditional economics would suggest - offshoring of manufacturing to a developing nation is associated 
with increased activities in higher-value activities by the offshoring firms back in the home country; or as knowledge-based theories and recent work from engineering would suggest - offshoring of manufacturing to a developing country is associated with reduced innovation. In contrast to classical economic trade theories, while offshoring is associated in some firms with increased innovation in other areas, in no case do we find offshoring associated with increased innovation in the industry's emerging technology. These results also differ from Vernon's seminal product cycle theory (Vernon, 1966) in two important and fundamental ways: First, the offshoring firms move manufacturing overseas much earlier in their product cycle than would be suggested by Vernon. Second, and most importantly, our results suggest that firms may be changing their innovation directions as a consequence of these earlier choices to move overseas. Specifically, in having the opportunity to move manufacturing overseas earlier in their product cycle, the firms may shift earlier from product to process innovation, slowing or stopping advance of the emerging technology by firms themselves and/or pushing those activities out to other industries, institutions or nations.

Our results also contribute to theory on the location of knowledge and the drivers of technology trajectories. While recent research has found that inventors will go to great lengths to persist in their research directions, despite institutional changes or other outside forces (Furman et al., 2012; Garud and Rappa, 1995; Klepper and Thompson, 2010), in our case, we find that the majority of individuals change research directions away from the emerging technology after changing firms. Meanwhile, firms and their strategies (both in offshoring and in hiring) dominate our story on innovation directions. These results suggest a strong role for firms and firm strategy both in driving innovation directions, and in constraining the corresponding opportunities faced by individuals.

\section{The Intersection of Offshoring with Theories on Industry Evolution, Individual Mobility, and Technology Change}

\subsection{Theories on Industry Evolution and Technology Trajectories}

A significant portion of the technology strategy literature emphasizes the role of the firm in identifying technology trajectories and driving innovation (Abernathy and Clark, 1985; Christensen, 1997; Henderson and Clark, 1990). According to product life cycle theories, many technologies start in a period of uncertainty about user preferences and technological means of satisfying them, during which there is significant firm entry and product innovation. Once a dominant design emerges, the focus of firm efforts switches from product to process innovation, ${ }^{1}$ and there is a shake-out in the number of producers (Abernathy and Utterback, 1978; Agarwal and Gort, 1996; Anderson and Tushman, 1990; Mueller and

\footnotetext{
${ }^{1}$ In a survey of 600 durable goods firms across 20 countries, Ettlie finds R\&D intensity and total quality management (e.g. process improvement) to be inversely correlated (Ettlie, 1997).
} 
Tilton, 1969; Tushman and Rosenkopf, 1992). Eventually, returns to investment in the prevailing technology fall as possibilities within the dominant paradigm are exhausted, setting the stage for a move to another generation of technology and a repetition of the cycle (Dosi, 1982; Foster, 1986; Gardiner, 1986; Sahal, 1985). This framework is not universally applicable. In some industries significant process improvements occur well before the emergence of a dominant design (Klepper and Simons, 2005).

Alternative mechanisms have been identified as being explanatory drivers of entry, exit, and innovation over the product life cycle including differences in firm innovative capability (Klepper, 1996, 2002; Sosa, 2009), prior firm experience (Klepper, 2002; Lourdes Sosa, 2013; Sosa, 2009; Sosa, 2011), firm size(Agarwal and Audretsch, 1999; Klepper, 1996), the timing of firm entry (Bayus and Agarwal, 2007), the experience of firm founders (Agarwal et al., 2004; Klepper and Simons, 2000), the innovation environment (Sarkar et al., 2006), and the evolution of markets (Agarwal and Gort, 1996; Klepper and Thompson, 2006). A technology's "limits" can also exceed those predicted (Christensen, 1993; Henderson et al., 1995; Utterback and Kim, 1985). This extended life can be determined not only by the structure of the dominant design and the laws of physics, but also by the needs and preferences of the technology's users, the capabilities of a technology's components, the evolution of key complementary technologies, and by increased innovation in the incumbent technology in response to the threat of a technological discontinuity (Foster, 1986; Henderson et al., 1995; Mowery and Rosenberg, 1979; Utterback, 1996).

\subsection{Theories on Human Capital and knowledge flows}

In contrast to the above literature, which focuses on the role of firms in technology evolution, a significant literature has also pointed to individuals as "active agents in the creation and spatial diffusion of knowledge" (Almeida and Kogut, 1999). This literature suggests that a firm's tacit knowledge is embedded in human capital (Berman et al., 2002; Hitt et al., 2001; Lepak and Snell, 1999; Szulanski, 1996), and that routines and resources transfer from old to new organizations through personnel migration (Aldrich and Pfeffer, 1976; Anton and Yao, 1995; Franco and Filson, 2006; Palomeras and Melero, 2010; Pfeffer and Leblebici, 1973; Rosenkopf and Almeida, 2003). Hiring firms can tap into the expertise of a worker's prior employer (Corredoira and Rosenkopf, 2010; Singh and Agrawal, 2011; Song et al., 2003) and employees from other firms also bring social capital in the form of external contacts from the time they were still in their prior workplace (Carnahan and Somaya, 2011; Dokko and Rosenkopf, 2010; Somaya et al., 2008). ${ }^{2,3}$ Evidence suggests that individuals may see value in participation in elite

\footnotetext{
${ }^{2}$ The benefits may be bi-directional: firms losing employees are more likely to subsequently cite patents of firms hiring these employees (Corredoira and Rosenkopf, 2010).

${ }^{3}$ Making hires that are technically distant, but not too distant, may be important to reaping knowledge benefits: Parrotta and Pozzoli (2012) find that the recruitment of skilled workers within an industry enhances the productivity of recipient firms. At the same time, Song, Almedia and Wu (2003)find that within the semiconductor industry
} 
technology direction-setting bodies (e.g. "Cooperative Technical Organizations") during periods of technological uncertainty, while organizations may not perceive this same value (Rosenkopf and Tushman, 1998). During technological discontinuities in the flight simulator_industry, Rosenkopf and Tushman find significant entry into CTOs and changes in affiliations by individuals (Rosenkopf and Tushman, 1998). In their 1999 paper, Almeida and Kogut find that "the ability to build upon semiconductor design knowledge is tied significantly to career paths of innovative individuals" (Almeida and Kogut, 1999). Further, a growing body of research has found that inventors will go to great lengths to persist in their research directions, despite institutional changes or other outside forces(Braum and MacDonald, 1978; Furman et al., 2012; Garud and Rappa, 1995; Klepper and Thompson, 2010).

Within this context, recent work has sought to understand the predictors of inventor mobility, and how formal and informal institutions may constrain this mobility and the associated transfer and creation of knowledge. Acquisitions, CEO changes, internal champions failing to convince existing leadership of the merit of their ideas, and other internal disagreements over the strategic direction of the firm or fundamental management practices are common reasons for employees - and especially top managers or top scientists and engineers - to leave a firm and found a spinoff (Klepper and Thompson, 2010).

Employees with higher earnings and performance are less likely to leave relative to employees with lower earnings, but if they do, they are more likely to create a new venture (Campbell et al., 2012; Carnahan et al., 2012). Formal and informal institutions, however, can limit the creation and diffusion of knowledge through mobility. Enforcement of non-competes attenuates mobility of executives (Garmaise, 2011), employee-inventors (Marx et al., 2009), and entrepreneurs (Stuart and Sorenson, 2003 \{Samila, 2011 \#435)\} and appears to drive inventors with greater human and social capital out of states that enforce noncompete agreements to those that do not (Marx et al., 2010). Ex-employees subject to non-competes are also most likely to take career detours, in which they involuntarily leave their technical field to avoid a potential lawsuit (Singh and Marx, 2013). Firm reputations for toughness in patent enforcement have likewise been found to reduce spillovers otherwise anticipated from departures of employee inventors, particularly when hiring organizations are entrepreneurial ventures (Agarwal et al., 2009). Litigiousness also shifts the distribution of talent released to the market: diminishing the proclivity of inventive workers to 'job hop' to other firms in the industry, while the most inventive workers still leave (Ganco et al., 2014).

Industry-wide offshoring of manufacturing provides an interesting setting within which to play out the above-described dynamics and the tensions between firm and individual roles in driving innovation directions, given institutional constraints.

mobility is more likely to result in inter-firm knowledge transfer when the hired engineers possess technological expertise distant from that of the hiring firm (Song et al., 2003). 


\subsection{Theories on Offshoring and knowledge flows: Manufacturing Location and the Locus of Innovation}

The global distribution of manufacturing value added has been shifting from developed to developing nations, driven in part by exponential increases in manufacturing value added in China (The World Bank, 2014). Vernon's seminal product cycle theory paper argued that firms will first produce in the North, close to the locus of innovation, and as the product standardizes and matures, its manufacturing will standardize and shift to developing nations with lower factor input costs (Vernon, 1966) ${ }^{4}$. Vernon's theory received empirical support through the 1980s (Antras, 2005; Mullor-Sebastian, 1983). By the late 1990s, however, more and more firms were being "born global," with some portion of their productive activities international from instantiation. As a consequence, today, offshore firms vary in their size, age, technology, and the very reasons they are offshore (Oviatt and McDougall, 1997).

The classical economic arguments for gains from trade suggest that the aggregate global productivity gains achieved through shifts in the locus of manufacturing will outweigh the losses (Ricardo, 1891), although redistribution policies may be necessary to compensate for the declining wages of lower-skilled individuals in some nations (Samuelson, 2004). Based on the law of comparative advantage, activities with higher labor content and lower skill requirements (such as labor-intensive manufacturing activities) would happen in the "South," while services and innovation occur in the "North." These arguments can be extended to the firm level: Movement of productive activities overseas helps firms free up resources to put into higher-value activities, like innovation, in the home nation (Agrawal and Farrell, 2003; Bardhan and Jaffee, 2005). Such division of labor can help firms increase efficiency and innovation (Arora et al., 2001; Baldwin and Clark, 2000).

Research by organizational and management scholars, however, suggest that offshoring may have adverse consequences for firms and home nation innovation. All else being equal, increased geographic distance, electronic dependence, time zone changes, and national differences have all been shown to reduce knowledge flows (Cummings et al., 2009; Gibson and Gibbs, 2006). In certain contexts - in particular, unfamiliar, unstructured problems- problem-solving requires experts being physically present to recognize embedded clues, exploit specialized tools, and find and interpret relevant information (Tyre and Von Hippel, 1997). These types of challenges have been particularly prevalent in the early years of process-based high-technology manufacturing industries such as electronic (Bassett, 2002; Holbrook et al., 2000; Lécuyer, 2006) and photonic (Fuchs and Kirchain, 2010) semiconductors, pharmaceuticals (Lécuyer, 2006; Pisano, 1997; Pisano and Shih, 2009), and the chemical industry (Hounshell, 1988).

\footnotetext{
${ }^{4}$ Vernon's product cycle theory offers an international-manufacturing-focused version of the product life cycle theories discussed earlier - where product innovation occurs first, along with significant firm entry, followed by process innovation, and industry consolidation.
} 
In addition, theories of agglomeration suggest that firms benefit from pecuniary (e.g. labor market) and knowledge externalities by locating near one another (Marshall, 1890). These theories have been extended to suggest that inter-firm "linkages" and the knowledge "commons" can be industry-specific; thus, once a critical mass of supplier and producer firms in an industry move, it becomes difficult to produce competitively elsewhere domestically (Cohen and Zysman, 1987; Pisano and Shih, 2009). Concerns have also been raised as to whether the offshoring of manufacturing will lead R\&D to follow. Here, the extent to which innovation can globalize may be technology-dependent: In the rare earth industry, catalyst innovations activities expanded globally while magnet innovation activities become more clustered, potentially due to differences in the locus and availability of knowledge globally for each (Fifarek and Veloso, 2010). Together, these challenges to knowledge transfer suggest that shifts in the locus of manufacturing may hurt domestic innovation (and, therewith, economic growth) in nations that lose manufacturing (Fifarek et al., 2008).

Recent work in engineering, however, has identified a different mechanism by which moving the locus of manufacturing overseas, and in particular to developing countries, may reduce innovation, domestically and globally, at least in the short- to medium-term (Fuchs et al., 2011; Fuchs and Kirchain, 2010). These results show that production characteristics (not just wages, but also yields, downtimes, materials, and the organization of production) can differ greatly across nations, so much so that they can change which products are profitable for firms to produce. In two cases--automobile bodies and high-end optoelectronic components - the authors find that when US firms shifted production to China and other countries in South and East Asia, the products based on the emerging technology that had been developed in the U.S. were no longer profitable. In both cases, these economics led the overseas firms to abandon producing these advanced products (Fuchs et al., 2011; Fuchs and Kirchain, 2010). In contrast to past work, which has focused broadly on innovation, this research suggests that differences in production economics may change incentives for technology development decisions, and thus technology trajectories. To-date, however, research has not followed up to see what happens to innovation in the emerging technology within these firms and to the human capital driving the emerging technology within them. Understanding these trends holds the potential to shed new insights into the relationship between offshoring, human capital, and technology evolution in the affected firms and industry.

\section{The Industry and Technology Context}

\subsection{The U.S., Optoelectronics, and Monolithic Integration}

Optoelectronics, which combines optic and electronic technologies, is expected to gradually replace pure electronics in information technology (OIDA, 2005; Schabel, 2005). Compared to electronics, optoelectronics enables components to have lower power consumption, higher data carrying 
capacity and no cross-talk problems by using photons instead of electrons to transmit information (Holden, 2003; OIDA, 2005; Shah, 2007). Optoelectronics is becoming increasingly central to meeting market requirements for higher bandwidth and reliable transmission in a wide range of applications. With basic advances in optoelectronics influencing applications not only in telecommunications but also in biomedical, military, computing and energy applications (OIDA, 2006; Shah, 2007), some might argue that optoelectronics can be considered a general purpose technology (GPT), wherein technical advance in the GPT for makes possible advances and complementary innovations across a broad spectrum of application sectors (Rosenberg and Trajtenberg, 2004). While GPTs are believed to have played a significant role in technological progress and economic growth, research suggests that a decentralized economy may have difficulty in fully exploiting the growth opportunities of GPTs (Bresnahan and Trajtenberg, 1995a; Bresnahan and Trajtenberg, 1995b).

Despite its social and economic promise, the optoelectronics component manufacturing industry has over the last three decades faced many challenges. In the 1980s and 1990s, as optoelectronics was revolutionizing telecommunications, a firm's competitiveness was a function of bringing the latest innovation to market. With the burst of the telecommunications bubble in March 2000, however, firm survival became a function of costs. With this shift in focus, many optoelectronic component manufacturers were faced with a dilemma: move manufacturing overseas to developing countries to reduce costs, or pursue an emerging technology, called monolithic integration, back in the U.S. that may enable them to have greater comparative advantage in the longer term in telecommunications and to move into larger markets beyond telecommunications such as computing, mobile, and sensing applications. (Fuchs and Kirchain, 2010)

\subsection{Integrated vs. Discrete (Non-integrated) Designs}

There are three competing designs today in optoelectronic device technology: monolithically integrated designs, hybrid designs, and discrete designs. Devices made with these three technologies are perfect substitutes in the telecommunications market, but not in other markets in the long term. Integrated designs combine different components onto one chip (Mickelson et al., 1997). Monolithic techniques produce all devices on a single substrate via fabrication processes including deposition, growth, and etching. Hybrid techniques, intead of using fabrication, bond different devices together using techniques such as flip-chip or bump bonding. In contrast to integration, discrete designs keep components on separate chips and connects the chips using assembly techniques such as wirebonding. Monolithic technology, which uses fabrication to integrate devices, is made during what is known as frontend manufacturing (or fabrication); hybrid and discrete technologies, which use assembly techniques to combine devices, are made during what is known as backend manufacturing (or assembly) (See Figure 1). 
While monolithic fabrication of multiple devices on a single chip was mastered several decades ago in electronic semiconductors for the case of transistors, it is in its infancy for the photonic semiconducting materials required in optoelectronic devices. Unlike electronics - where monolithic integration is of devices with similar material compositions, in optoelectronics, monolithic integration requires the fabrication of devices with often vastly different material compositions. This type of fabrication poses significant scientific challenges. The potential benefits of monolithic integration, however, are equally significant. Monolithic integration reduces the size of the device (compared to hybrid or discrete technologies) - thus enabling the many advantages of optoelectroincs to be applicable in new, and much larger markets beyond telecommunications where device size can be central. As such, monolithic integration might be thought of as a general purpose technology enabler - providing optoelectronics the potential to expand into a broad array of new markets.
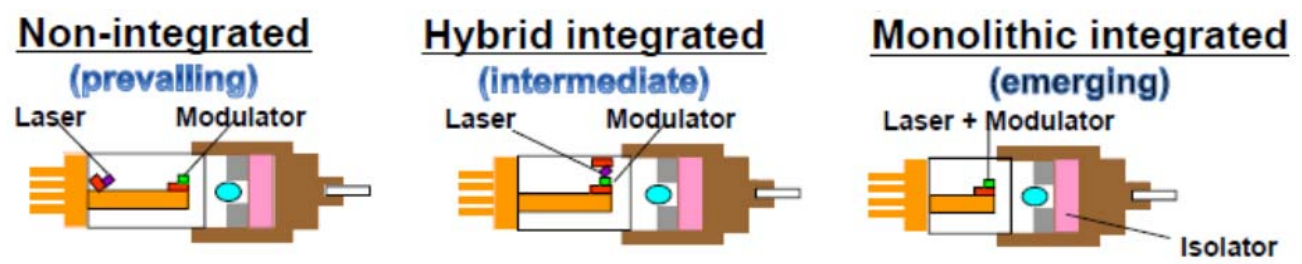

Figure 1 Three competing designs today in optoelectronic device technology

We plotted innovation activities in optoelectronics integration (monolithic and hybrid) in different nations based on USPTO patents to understand the role of the U.S. in integration internationally. With respect to the institutions leading innovation in integration, firms dominated, making up $91 \%$ of the global patent assignees. The U.S. firms, followed by Japanese firms ${ }^{5}$, produced almost half of the patents in integration between 1973 and 2006. In addition to being the top annual and cumulative patentor of integrated technologies, U.S. firms are also the vanguards in integrated technology innovation - having started patenting in optoelectroincs integration in 1973, five years prior to any other nation ${ }^{6}$. Thus understanding the technology directon of U.S. firms is also an important part of understanding trends internationally. With respect to market applications, in the U.S., firms focused on selling to the telecommunications market begin to lead patenting in integration as of the early 1990s, and by 2000 through the end of our period of study, small and medium-sized firms focused on telecommunications applications (e.g. the focus of our study) dominate U.S. patenting in integration.

In Fuchs 2010, the emerging "integrated" design refers to monolithic integration. Fuchs 2010 does not address hybrid technologies. The USPTO patent class for integration (385/14) includes both hybrid and monolithically integrated patents. In this paper, we hand-classify all integrated patents by

\footnotetext{
${ }_{6}^{5}$ Japanese firms hold just over $30 \%$ of cumulative patents in integration (monolithic and hybrid) for the period of our study.

${ }^{6}$ U.S. firms started patenting in integration in 1973, followed by Germany (1978), Italy (1978) and Canada (1979).
} 
optoelectronic component manufacturers into monolithic or hybrid so we can treat them as separate response variables.

\subsection{The Economics of Offshoring and Technology Directions in Optoelectronic Components}

In the case of the optoelectronic industry, manufacturing overseas in developing countries reduces firms' overall production costs for discrete designs (see Figure 2). As can be seen in Figure 2, while the emerging, monolithically integrated optoelectronic component technology is cheaper to produce if manufacturing is in the U.S.; the prevailing, discrete technology is cheaper to produce if manufacturing is in developing East Asia. Production characteristics (wages, yields, downtimes, materials, and the organization of production) differ between the U.S. and the developing East Asia, changing which product developments are profitable for firms to pursue. Most importantly, the cost of producing the discrete optoelectronic technology in Developing East Asia is lower than the cost of producing the monolithic optoelectronic technology onshore back in the U.S. Thus, manufacturing the discrete device in developing East Asia is the global optimum for firms from the perspective of minimizing production costs. It is important to note that the above-described economics are specific to offshoring - moving manufacturing overseas to a different nation, in this case, to a developing country. As national differences drive the above results, Fuchs and Kirchain find the same effect regardless of whether the firm is offshoring manufacturing in-house or at a contract manufacturer (offshore outsourcing). Further, we would not expect onshore outsourcing to portray the economics in Figure 2. (Fuchs and Kirchain, 2010)

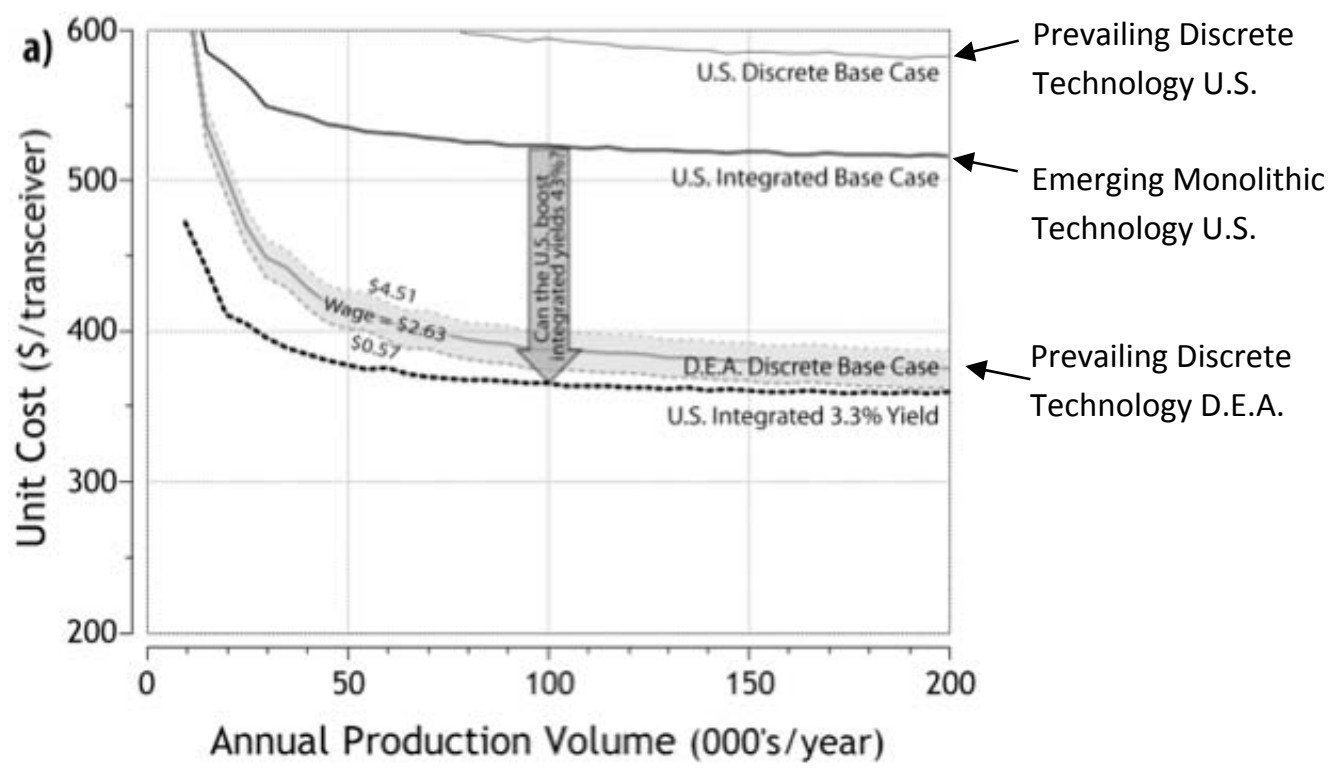

Figure 2 Offshoring can reduce or remove firms' economic incentives for developing the emerging technology (monolithic integration). (Fuchs and Kirchain, 2010) 
These economics alone, however, may not be enough to change the trajectory of firms. A number of additional factors reduce optoelectronic firms' incentives and capability to develop the emerging, monolithically integrated, technology (Fuchs and Kirchain, 2010): First, with production of the discrete device in developing East Asia the cheapest alternative globally, and the smaller size of monolithically integrated devices not highly valued in telecommunications at the time of offshoring, firms may choose to focus at first on cost-competing in the telecommunications market with their existing customers rather than pursuing uncertain opportunities in new markets that may require the size advantages of monolithic integration. Second, as an early-stage technology, the science underlying the production of high-end monolithically integrated devices is not well understood, and the process is more an art than a science. Yields are low, and fabrication engineers are regularly on the production line. In addition, there is currently a lack of R\&D engineers with monolithic integration capabilities in developing East Asia. Third, the optoelectronic component market is currently too small to support individual firms having multiple manufacturing facilities. As a consequence, firms are likely forced to choose between producing discrete and hybrid designs in developing East Asia (and having the most competitive costs), or pursuing monolithically integrated devices in the U.S. in the hopes of securing access to larger, long-term markets.

\section{Methods}

\subsection{Research Structure}

This research inductively derives new theoretical insights from a combination of quantitative and qualitative data. (For other examples of similar approaches see (Cohen et al., 2012; Fernandez-Mateo, 2009; Kellogg and Smith, 2009). This grounded theory-building process requires iteration between data and theory (Eisenhardt, 1989; Glaser and Strauss, 1967). Our unit of analysis is the industry - here, U.S. optoelectronic component manufacturers for telecommunications - and the firms and inventors therein. We explore in particular whether (1) due to different offshore production economics, firms who move manufacturing offshore slow U.S.-based R\&D activities in an emerging technology (monolithic integration) and (2) the inventors originally within these offshoring firms, leave, and continue innovating in the emerging technology at different institutions. In pursuing these questions, we do not seek to infer causal relationships, rather to build theory. Indeed, we believe that some of the more interesting aspects of this story are its endogeneities, and that the description of that story in and of itself contributes to existing debates in the literature on industry evolution, inventor mobility, and technology trajectories. (For other examples of non-causal studies leveraging descriptive analyses of quantitative data see(Brown and Medoff, 2003; Ouimet and Zarutskie, 2011) in addition to the authors listed earlier in this paragraph.) 


\subsection{Data Sources}

To explore the hypotheses in the preceding section, we triangulate data from industry archives, buyers guides, SEC filings, phone-based surveys, inventor resumes, and hand-classified USPTO patent data to quantify firms' and individuals' innovation activities, firms' extent of offshoring and other control variables at the firm-level and individual-level.

\subsubsection{Dependent Variable - Innovation Activities}

To quantify firms' and individuals' innovation quantity ${ }^{7}$ and direction ${ }^{8}$, we use patent data from the USPTO database. While not without limitations, patents have been shown to be a reasonable indicator of innovation activities (Hall et al., 2001), including as proxies for firm (Fifarek et al., 2008) and individual (Fleming et al., 2007) innovation, and to track the mobility of the patent holder (Almeida and Kogut, 1999).

The USPTO patent database classifies each patent into one or more technical classes and subclasses related to its invention (Hall et al., 2001; 2010; USPTO, 2010). Based on this classification system, its detailed definitions for each class, as well as the contextual expertise in optoelectronics of one of our authors, we hand-identified patent classes and subclasses within the field of optoelectronics as well as which of those patents qualify as being in integration (hybrid and monolithic). We identified in total 11 classes associated with optoelectronics innovation" and one subclass 385/14, titled "Integrated Optical Circuit", that covers integrated optoelectronics technologies ${ }^{10}$. According to our classification, there are 196,439 optoelectronic patents and 3,326 integrated patents (monolithic and hybrid) in total in the USPTO database up through December 2010. Our focus firms (firms identified as being within our research scope (see 3.1.5)) have 4737 optoelectronic patents and 340 integrated patents. We manually classified the 340 integrated patents into monolithic and hybrid designs leveraging the expertise of one of our authors along with a research assistant with a bachelor's degree in materials science. Based on this hand-classification, our focus firms have 209 monolithic integrated patents and 131 hybrid integrated patents. Using the same method, we also hand-classified the integrated patents granted to our target inventors at firms they worked in before and after our focus firms into monolithic versus hybrid.

While USPTO patent data can serve as a proxy for firms' and individuals' innovation activities in certain technology fields, the USPTO database has many challenges, including ambiguities in the names of assignees and inventors (Bessen, 2009; Hall et al., 2001; Li et al., 2014). These ambiguities come from many sources, including misspellings and other inconsistencies (i.e. middle names, alias, initials, acronym,

\footnotetext{
${ }_{8}^{7}$ Here, quantity refers to the total number of patents as well as the rate of patenting.

${ }^{8}$ Here, direction refers to optoelectronic component innovation in monolithic, hybrid or non-integrated technologies.

${ }^{9}$ The patent classes and subclasses that we identified as optoelectronics are 250/220-339 and 551, 257/13, 21, 52-56, 59, 79-103, 113-118,184-189, 225-234, 257-258, 290-294 and 431-466, 353/, 356/, 359/, 372/, 385/, 398/, 438/24-25 and 27, 720/ and G9B/7.

${ }^{10}$ This subclass, $385 / 14$, includes a wide range of integrated designs covering both monolithic and hybrid designs.
} 
and abbreviations). We use the disambiguated Fuchs Lab Optoelectronics Patent Database (Ventura et al., 2014) as a starting point and hand-clean all data associated with our firms and inventors.

Finally, it is important to note that there can be a multiple-year gap between the time patents were filed and the time they were issued. While only $22.24 \%$ of patents come out in the first year, $99.41 \%$ of patents come out after five years. In an attempt to address the above issue, we collected firms' patent applications for the 2000-2011 period. Our goal in collecting this data was to determine feasibility of an extended time period beyond our current 2006 cut-off (due to the delay between patents being filed and patents being granted). We found that the current available application data from the USPTO database is unfortunately not suitable to extend the length of our observation period due to firms withholding their applications from being made public. Thus for the analyses in this paper, we exclude data post-2006.

\subsubsection{Independent Variable - Extent of Offshoring}

As used in this paper, offshoring is the relocation of manufacturing facilities from a home, developed country to a developing country. Our primary measure of offshoring is the number of years that a firm has a particular type of manufacturing (assembly or fabrication) overseas in a developing country. ${ }^{11,12}$ We gathered public firms' offshoring information (i.e. offshoring dates, applications, and manufacturing sites) from Securities and Exchange Commission (SEC) filings. We also conducted surveys with private and public firms to collect all data missing from SEC filings. To gather this data, we created a survey questionnaire that we sent in advance to the firms, and then completed with a representative from each company by phone. As a consequence, among other items, in our analyses we are able to distinguish between the number of years that only assembly activities and the number of years that both assembly and fabrication activities were overseas in a developing country.

\subsubsection{Control Variables}

To understand the individual firm environment within which the firms are operating, we also collect annual firm revenues, profits, R\&D expenditures, employee numbers, and merger and acquisition data from SEC filings and the previously-mentioned surveys with representatives from each firm. In addition, to take into account the overall industry and technical environment we include controls for the burst of the telecommunications bubble and for field-wide patent productivity in general optoelectronics as well as in optoelectronics integration. Finally, to better track individuals' mobility, we collect the professional resumes of our target integration inventors ${ }^{13}$. (See section 4.2.6 for discussion of our inventor

\footnotetext{
${ }^{11}$ We describe our independent variable as "extent" of offshoring rather than, for example, "duration" of offshoring, as our interviews with the companies suggested that the offshoring firms increased the amount of products produced in the offshore facility, the longer they had that facility.

${ }^{12}$ In our robustness analyses, we also look at offshoring instead as a dummy variable, where the measure is yes / no for each type of offshoring - assembly and fabrication - at a given time t.

${ }^{13}$ In total we were able to collect 39 of our 106 target integration inventors' resumes. We leveraged inventor contact information provided to us by the top three professional societies in optics. When we were able to reach inventors by phone or email, we
} 
scope.) These resumes, which complement the patent data, allow us, when available, to locate inventors accurately between patents and even if they stop patenting or migrate to other fields.

\subsubsection{Scope Definition}

This study focuses on small and medium sized U.S. firms that manufacture active optoelectronic components for telecommunication applications and inventors who have patented within these firms.

\subsubsection{Firm Sample}

We triangulated multiple years of published data from seven different sources spanning industry market analyses, buyer's guides, trade association workshops, trade fair publications, and the USPTO patent database, to identify all firms manufacturing optoelectronic components for the telecommunications industry ${ }^{14}$. The raw sources cover different countries, institutions (e.g. firms, government entities, and universities) and market scopes. We therefore manually classified institutions by type (firm or not) and then firms by country (US headquarters or not) and application (telecommunications or not). We also wanted to make sure not to overlook firms with innovation activities targeting the same industry, but not yet sufficient market presence to show up in the above sources. After interviews with industry experts we triangulated two sources, OVUM market reports (our only source that focused exclusively on firms aiming to make optoelectronic components for telecommunications) and the USPTO database, to identify any remaining optoelectronic component firms in telecommunications that may not yet have sales (or show up in the above sources) but work on integration (monolithic or hybrid). From this data, we were able to identify 16 firms having at least one integrated patent (monolithic or hybrid) who also reported in the OVUM market reports and another 12 firms having three or more integrated patents (monolithic or hybrid) that do not show up in the OVUM market reports but were focused on selling optoelectronic components to the telecommunications market ${ }^{15}$. (See Table 1) We reviewed this final list of firms with three long-time industry experts to confirm our list was both appropriate and complete.

would ask them to send us their resumes directly. We also were able to reach several inventors on LinkedIn. Again, in reaching out them we requested their most current resume. In cases where they didn't respond we used the data posted on LinkedIn.

${ }^{14}$ Sources and Years: Ovum Annual Telecommunications Industry Optoelectronic Component Manufacturers Annual Revenue and Market Share Survey (2005-2009), LightCounting Optical Transceiver and TOSA/ROSA Vendor List (2010), Reed "Optoelectronics - A Strategic Study of the Worldwide Semiconductor Optoelectronic Component Industry to 2008" (20032005), Strategies Unlimited "Opto 50 - A Review of the World's Leading Manufacturers of Semiconductor-Based Optoelectronic Components 2000" (1998-1999), The Optical Society of America (OSA) OFC Buyers' Guides (2004-2009), Optoelectronics Industry Development Association (OIDA) Optoelectronic Component Manufacturers for Telecommunications Workshop Attendee List (1998, 2005), United States Patent and Trademark Office (USPTO) (1976-present)

${ }^{15}$ We used having one integrated patent (monolithic orand hybrid) as thea threshold for including firms from the OVUM market report to filter out those that never worked on integration even if they have significant market share. We used having three integrated patents (monolithic orand hybrid) as our initial criteria in the USPTO database as the criteria to select highly innovative firms. We then used a combination of web and database searches to confirm if the USPTO-identifiedse firms are wereU.S. firms targeting selling optoelectronic components to the telecommunications market. For both the OVUM and the USPTO databases we used publically available resources on the web to confirm which firms had U.S. headquarters., and were thus appropriate to our scope. Finally, we triangulated our results against our five other data sources before finalizing our selection of the 28 firms. 
Table 1 Research Firm Scope ${ }^{16}$

\begin{tabular}{|c|c|c|c|c|c|c|c|}
\hline \multicolumn{4}{|c|}{ Firms Manufacturing Anything Offshore by 2009} & \multicolumn{4}{|c|}{ Firms Manufacturing Solely Onshore by 2009} \\
\hline Name & $\begin{array}{l}\text { Total } \\
\text { Int. } \\
\text { Patent }\end{array}$ & $\begin{array}{l}\text { Total } \\
\text { Monolithic } \\
\text { Patent }\end{array}$ & $\begin{array}{l}2009 \\
\text { Revenue ** }\end{array}$ & Name & $\begin{array}{l}\text { Total Int. } \\
\text { Patent }\end{array}$ & $\begin{array}{l}\text { Total } \\
\text { Monolithic } \\
\text { Patent }\end{array}$ & $\begin{array}{l}2009 \\
\text { Revenue }\end{array}$ \\
\hline Finisar $\grave{\dagger}$ & 28 & 8 & $\$ 541 \mathrm{M}$ & Infinera & 70 & 67 & $\$ 309 \mathrm{M}$ \\
\hline Bookham $\dagger$ & 25 & 20 & $\begin{array}{l}\text { Merged } \\
(2008)\end{array}$ & Lightwave * & 20 & 13 & $\begin{array}{l}\text { Acquired } \\
\text { (2003) }\end{array}$ \\
\hline JDSU $\dagger$ & 22 & 12 & $\$ 1.29 \mathrm{~B}$ & Prima Luci * & 6 & 3 & $\begin{array}{l}\text { Not } \\
\text { Available }\end{array}$ \\
\hline Agilent & 22 & 9 & $\$ 4.48 \mathrm{~B}$ & SDL & 5 & 5 & 2001 \\
\hline Avago & 16 & 2 & $\$ 1.48 \mathrm{~B}$ & LNL * & 4 & 3 & $\begin{array}{l}\text { Exited } \\
(2004)\end{array}$ \\
\hline Agere $\dagger$ & 14 & 9 & $\begin{array}{l}\text { Acquired } \\
\text { (2007) }\end{array}$ & Optronx * & 4 & 0 & $\begin{array}{l}\text { Exited } \\
(2002)\end{array}$ \\
\hline Avanex $\uparrow$ & 13 & 11 & $\begin{array}{l}\text { Merged } \\
(2008)\end{array}$ & $\begin{array}{l}\text { Teraconnect } \\
*\end{array}$ & 4 & 0 & $\begin{array}{l}\text { Exited } \\
(2003)\end{array}$ \\
\hline Emcore $\dagger$ & 11 & 3 & $\$ 176 \mathrm{M}$ & Xponent * & 4 & 3 & $\begin{array}{l}\text { Acquired } \\
\text { (2007) }\end{array}$ \\
\hline $\begin{array}{l}\text { NeoPhotonics } \\
*+\end{array}$ & 10 & 10 & $\$ X X M$ & LSI & 3 & 2 & $\$ 2.22 \mathrm{~B}$ \\
\hline TriQuint $\dagger$ & 8 & 4 & $\$ 654 \mathrm{M}$ & Axsun * & 2 & 0 & $\begin{array}{l}\text { Not } \\
\text { Available }\end{array}$ \\
\hline Kotura $* \dagger$ & 7 & 5 & \$XX M & & & & \\
\hline $\mathrm{OCP} \uparrow$ & 4 & 2 & $\begin{array}{l}\text { Acquired } \\
(2007)\end{array}$ & & & & \\
\hline Picolight $* \dagger$ & 4 & 4 & $\begin{array}{l}\text { Acquired } \\
\text { (2007) }\end{array}$ & & & & \\
\hline AFOP & 2 & 0 & $\$ 30 \mathrm{M}$ & & & & \\
\hline CyOptics *† & 2 & 0 & $\$ X X M$ & & & & \\
\hline Oplink $\dagger$ & 2 & 1 & $\$ 144 \mathrm{M}$ & & & & \\
\hline Opnext $\uparrow$ & 2 & 0 & $\$ 319 \mathrm{M}$ & & & & \\
\hline New Focus $\dagger$ & 1 & 0 & $\begin{array}{l}\text { Acquired } \\
\text { (2003) }\end{array}$ & & & & \\
\hline
\end{tabular}

\subsubsection{Inventor Sample}

Besides firm activities, we also explore the activities of individuals with one or more optoelectronics patents within our 28 focus firms. We divide the inventors who patent at our focus firms into a target group and two control groups: Our target group is inventors at our focus firms with strong capabilities in integration (more than two integrated patents), in other words our "focus inventors". In addition we have two other groups: 1) integration "dabblers" - (inventors at our focus firms who only have one or two integrated patents, and 2) a control group of non-integrated inventors (inventors at our focus firms who do not have integrated patents). We chose the cut-off of three integrated patents (monolithic or hybrid) based on statistically significant differences we were seeing in inventor activity between inventors with more

\footnotetext{
${ }^{16}$ Within these 28 focus firms, as of 2011, 12 of the firms no longer exist - four of them exited, two merged with each other, six were acquired, and one was diversified.
} 
than two integrated patents versus those with fewer. We see this cut-off as representing the difference between inventors who have strong interest or capabilities in integration innovation (monolithic or hybrid), versus those who may have had brief involvement in a related project. We have in our target group 106 "focus" inventors (with more than two patents in integration). Of these focus inventors with strong capabilities in integration, 99 have one or more monolithic patents, and seven have only hybrid patents. In our two control groups we have 383 integration "dabblers" with two or fewer patents in integration, and 2907 non-integrated inventors.

Within our integrated inventor group, we divide the integration inventors into four subgroups: those who have monolithic patenting experience at our focus firms, those who have monolithic patenting experience prior to being our focus firms but no monolithic patents at our focus firms, those who have monolithic experience only post being in our focus firms (and no monolithic patents prior to or at our focus firms), and those who only have hybrid patents at our focus firms and no prior or post monolithic patenting experience. We further divided each of the above integration subgroups into two parts: those who ever worked at offshoring and those who never worked at offshoring firms. In the non-integrated group, we also divided the inventors into the same two parts: those who ever worked at an offshoring firm and those who never worked at an offshoring firm. We use t-tests to check whether observed differences across the groups are statistically significant.

\subsection{Firm Regression Models}

Our primary focus is on the relationship between patenting and going offshore. We present two main regression analyses, plus a third regression as a part of our robustness analysis. First, we model the relationship between the firms' number of yearly patents and the extent of their offshoring using a negative binomial regression (while controlling for firm size, R\&D strategy, the burst of the telecommunications bubble, and the current state of innovation in the field). This approach correctly models the distribution of our patent count data and treats the firms' yearly patents as individual observations. ${ }^{17}$ We then turn to a Cox proportional hazards regression to model the instantaneous rate of patenting over time. This model accounts for a non-constant patenting rate over the year and allows for firm longitudinal effects over time. Third, as part of our robustness checks, we use a Cox proportional hazards regression to model whether a firm's the risk of going offshore each year is associated with its innovative capability prior to offshoring. This model uses cumulative patent counts to represent innovation capability and similarly controls for firm size, R\&D strategy, the burst of the telecommunications bubble, and the current innovation status of the field. The variables and subscripts we use in the models that follow are defined in Table 2. In addition to our quantitative analysis, we leverage

\footnotetext{
${ }^{17}$ In addition to matching the distribution of our patent count data, a negative binomial model is also particularly appropriate for our data given the large number of firm-years with zero-patents, especially in monolithic and hybrid patenting.
} 
the full descriptive data available through the SEC filings and firm surveys to gain additional insights into each firm and inform our interpretation of the quantitative results. Finally, we incorporate insights from this descriptive analysis back into our regression models in terms of fixed effects for firm strategies.

\subsubsection{The Relationship between offshoring and innovation}

\subsubsection{Negative Binomial Models}

We use negative binomial models ${ }^{18}$ to gain insight into the relationship between firms' innovation activities (monolithic, hybrid and non-integrated patent numbers) and their extent of offshoring (number of full years only assembly activities and number of full years both assembly and fabrication activities are offshore). In these models, since moving facilities and products overseas does not happen within a single night or even a single month and often firms have their old facility still running in the home country for the first few months, we define the first "full" year of offshoring as the year after offshoring is documented in the SEC filings or firm surveys. In addition, for both our offshoring and our R\&D spending variables, we then use a one-year-lag to account for the delay between when R\&D is conducted and subsequent patenting activities ${ }^{19}$. As the role a firm's revenue in a given year may play in its R\&D outcomes that same year versus the next is less clear ${ }^{20}$, we use an unlagged revenue variable in our main model, but explore using instead a lagged revenue variable in our robustness tests. We consider a firm's yearly revenue as a proxy of firm size ${ }^{21}$ and its yearly R\&D spending as a proxy of firms' R\&D strategy. We use the total U.S. integrated patent numbers (monolithic and hybrid) and non-integrated patent numbers as proxies for the overall innovation environment in the regressions with integrated and nonintegrated patents as the dependent variable, respectively. We also control for the burst of the telecommunications bubble. Our negative binomial regression model at the firm level is as follows:

$$
P_{a, y}=\beta_{0}+\beta_{1} A_{y-1}+\beta_{2} B_{y-1}+\beta_{3} Q_{y}+\beta_{4} R_{y-1}+\beta_{5} F_{b, y}+\beta_{6} T_{y-1}
$$

In addition to controlling for possible confounding firm effects, we also include firm fixed-effect variables in our negative binomial regressions to analyze the effect within firms. As part of our robustness analyses we also explore measuring offshoring instead as a dummy variable.

\footnotetext{
${ }^{18}$ The distribution of patent numbers is right-skewed count data; therefore we use a negative binomial regression model.

${ }^{19}$ We learned from our interviews that it takes on average one year after R\&D is started for patents to be filed. Thus we would expect the effect of offshoring not to appear immediately but one year later. Similarly, we assume R\&D spending this year will affects firms' next year patent productivity.

${ }^{20}$ Since there is some relationship between R\&D spending and revenue, it could be argued to be appropriate to lag the revenue data, as well. That said, revenue in a given year may also affect how many patents a firm can afford to file in that year, and then not lagging the revenue data could be argued to be appropriate.

${ }^{21}$ The other possible proxy of firm size is employee number. We have employee numbers from 16 firms and 112 observations for employee data (but revenue data from 19 firms and 158 observations for revenue information). Also, the lack of employee numbers for certain firms in certain years would force us ignore some main integration producers, like Infinera.
} 
Table 2 Variables and Subscripts (Firm Regressions)

\begin{tabular}{|c|c|c|c|}
\hline Subscript & Description & Purpose & Role \\
\hline Y & Year & & \multirow{3}{*}{$\stackrel{\Xi}{\Xi}$} \\
\hline $\mathrm{D}$ & Day & & \\
\hline$y(d)$ & Year for the day on which a firm filed a patent & & \\
\hline A & $\{$ monolithic, hybrid, non-integrated $\}$ & $\begin{array}{l}\text { Type of patent } \\
\text { (hand classified) }\end{array}$ & \multirow{2}{*}{ 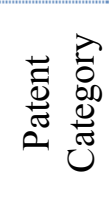 } \\
\hline B & $\{$ integrated, non-integrated $\}$ & $\begin{array}{l}\text { Field-wide type of } \\
\text { patent }\end{array}$ & \\
\hline Variable & Description & Purpose & Role \\
\hline $\mathrm{P}_{\mathrm{a}, \mathrm{y}}$ & Patent count for year (y) of patent type (a) & Yearly innovation & \multirow{3}{*}{ 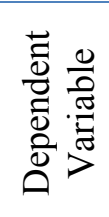 } \\
\hline $\mathrm{h}_{\mathrm{pat}, \mathrm{a}}(\mathrm{d})$ & Risk of patenting in day (d) of patent type (a) & Innovation risk & \\
\hline $\mathrm{h}_{\mathrm{off}}(\mathrm{y})$ & Risk of moving any facilities offshore in year (y) & Offshoring risk & \\
\hline $\mathrm{C}_{\mathrm{a}, \mathrm{y}}$ & Cumulative patent count in year (y) of patent type (a) & $\begin{array}{l}\text { Existing innovation } \\
\text { capability }\end{array}$ & \multirow{5}{*}{ 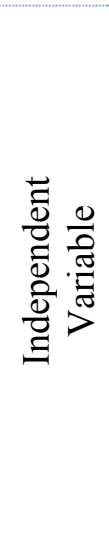 } \\
\hline $\mathrm{A}_{\mathrm{y}-1}$ & $\begin{array}{l}\text { Number of full years that firm has only assembly activities } \\
\text { offshore (y-1: one year lag) }\end{array}$ & \multirow{4}{*}{$\begin{array}{l}\text { Extent of } \\
\text { offshoring }\end{array}$} & \\
\hline $\mathrm{B}_{\mathrm{y}-1}$ & $\begin{array}{l}\text { Number of full years that firm has both assembly and } \\
\text { fabrication activities offshore } \\
\text { (y-1: one year lag) }\end{array}$ & & \\
\hline $\mathrm{A}_{\mathrm{y}(\mathrm{d})-1}$ & $\begin{array}{l}\text { Number of full years that a firm has only assembly } \\
\text { activities offshore }(y(d)-1 \text { : one year lag) }\end{array}$ & & \\
\hline $\mathrm{B}_{\mathrm{y}(\mathrm{d})-1}$ & $\begin{array}{l}\text { Number of full years that a firm has both assembly and } \\
\text { fabrication activities offshore } \\
\text { (y(d)-1: one year lag) }\end{array}$ & & \\
\hline $\mathrm{h}_{0}(\mathrm{y})$ & $\begin{array}{l}\text { Unspecified baseline rate in Cox offshoring rate models } \\
\text { for year }(y)\end{array}$ & \multirow[t]{2}{*}{ Baseline risk } & \multirow{13}{*}{ 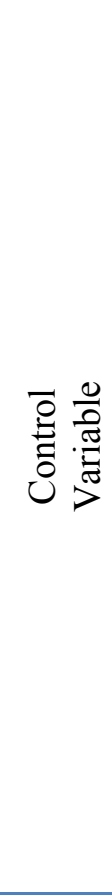 } \\
\hline $\mathrm{h}_{0}(\mathrm{~d})$ & $\begin{array}{l}\text { Unspecified baseline rate in Cox patent rate models for } \\
\text { day (d) }\end{array}$ & & \\
\hline $\mathrm{Q}_{\mathrm{y}}$ & Revenue for year (y) & & \\
\hline $\ln Q_{y}$ & Natural logarithm value of Revenue for year (y) & Firm size & \\
\hline $\ln Q_{y(d)}$ & Natural logarithm value of Revenue for year $(\mathrm{y}(\mathrm{d}))$ & & \\
\hline $\mathrm{R}_{\mathrm{y}-1}$ & $\mathrm{R} \& \mathrm{D}$ spending for year (y-1: one year lag) & \multirow{3}{*}{ Firm R\&D strategy } & \\
\hline $\ln R_{y}$ & Natural logarithm value of R\&D spending for year (y) & & \\
\hline $\ln R_{y(d)-1}$ & $\begin{array}{l}\text { Natural logarithm value of R\&D spending for year }(y(d)) \\
(y(d)-1 \text { : one year lag) }\end{array}$ & & \\
\hline $\mathrm{F}_{\mathrm{b}, \mathrm{y}}$ & $\begin{array}{l}\text { Total patents in the U.S. technical field of optoelectronics } \\
\text { for year (y) of patent type (b) }\end{array}$ & $\begin{array}{l}\text { Trends of technical } \\
\text { field }\end{array}$ & \\
\hline $\mathrm{F}_{\mathrm{b}, \mathrm{y}(\mathrm{d})}$ & $\begin{array}{l}\text { Total patents in the U.S. technical field of optoelectronics } \\
\text { for year }(y(d)) \text { of patent type (b) }\end{array}$ & $\begin{array}{l}\text { Trends of technical } \\
\text { field }\end{array}$ & \\
\hline $\mathrm{T}_{\mathrm{y}}$ & Telecom bubble dummy variable for year (y) & Telecom bubble & \\
\hline $\mathrm{T}_{\mathrm{y}-1}$ & $\begin{array}{l}\text { Telecom bubble dummy variable for year }(y) \\
\text { (y-1: one year lag) }\end{array}$ & Telecom bubble & \\
\hline $\mathrm{T}_{\mathrm{d}-365}$ & $\begin{array}{l}\text { Telecom bubble dummy variable for day }(\mathrm{d}) \\
\text { (d-365: one year lag) }\end{array}$ & Telecom bubble & \\
\hline
\end{tabular}




\subsubsection{Cox Proportional Hazard Model}

In addition to using negative binomial patent count models, we also model the firms' patenting rates using Cox proportional hazards regression with repeated events clustered by firm (Sorensen and Stuart, 2000; Sosa, 2009; Sosa, 2011). Unlike the negative binomial model, this approach does not assume that the patent rate is constant over a year or that a firm's numbers of patents each year are independent. Instead we analyze the risk of an event happening (here, a particular type of patenting ${ }^{22}$ ) to a particular firm over time. As in Sosa 2011, we define the initial risk of a firm patenting as starting on the day before the firm's first accepted patent application file date. The risk of subsequent patenting events starts instantly after the previous event happens (Sosa, 2011). We model the risk of patenting for each type of technology (monolithic, hybrid, or non-integrated) as follows:

$$
h_{p a t, a}(d)=h_{0}(d) \exp \left(\beta_{1} A_{y(d)-1}+\beta_{2} B_{y(d)-1}+\beta_{3} \ln Q_{y(d)}+\beta_{4} \ln R_{y(d)-1}+\beta_{5} F_{b, y(d)}+\beta_{6} T_{d-365}\right)
$$

In this model we use the same control variables as the negative binomial model - revenue, R\&D expenditures, total patenting in the field of optoelectronics (integrated versus non-integrated), and the burst of the telecommunications bubble. We use the natural log of revenue and R\&D spending, highly right-skewed variables, in our patent rate model to improve model fit. (R\&D spending remains lagged by one year.) While the dependent variable is a daily measure, these controlled variables, except for the telecommunications bubble burst, are measured yearly.

\subsubsection{Relationship between innovation capability and risk of offshoring}

One potential explanation (other than offshoring itself having a negative impact on innovation in monolithic integration) for why offshoring might be associated with reduced patenting in monolithic integration is that firms with lesser capabilities are the ones that go offshore. As part of our robustness analyses, to explore this potential explanation, we use Cox proportional hazard regressions to model the risk of a firm going offshore given the firm's innovation capability (monolithic, hybrid, and nonintegrated cumulative patent numbers). We set the start of risk for going offshore for each firm as the year when the firm first provides financial data (with the exception of one firm whose financial data was available for a full decade prior to the other firms - we set this firms start date 1992 for consistency with the general observation period for the other firms). We observe each firm yearly until either the firm has exited the market or 2006, the end of our observation period. In this model, going offshore is defined as moving any type of facility (assembly or fabrication) offshore. We model the risk of going offshore as follows:

$$
\begin{gathered}
h_{\text {off } f}(y)=h_{0}(y) \exp \left(\beta_{1} C_{m o n, y}+\beta_{2} C_{h y b, y}+\beta_{3} C_{n o n-i n t, y}+\beta_{4} \ln Q_{y}+\beta_{5} \ln R_{y}+\beta_{6} F_{\text {int }, y}\right. \\
\left.+\beta_{7} F_{n o n-i n t, y}+\beta_{8} T_{y}\right)
\end{gathered}
$$

\footnotetext{
${ }^{22}$ Our USPTO data sources allow us to access the precise day a patent was filed, by which we indicate an event happening.
} 
We continue to use the natural log of revenue and R\&D spending to improve model fit. Unlike the previous negative binomial and patent rate hazard models, we do not lag our R\&D spending as we do not expect the same delayed effect on offshoring that we would expect for patents. We include for all three technology types firm cumulative patent numbers as proxies for the firms' innovation capabilities prior to going offshore. As in the previous models, we include controls for the burst of the telecommunications bubble and all integrated or non-integrated optoelectronics patents in each year in the U.S.

\subsection{Individual Regression Models: Probability an Inventor will go to Infinera}

We use a cox proportional hazard function to model an inventor's risk of going to Infinera as a function of the status of their current firm (in the industry and manufacturing onshore, in the industry and manufacturing offshore, or outside the industry), prior mobility (measured as number of assignee changes prior to going to Infinera), innovation capabilities in the emerging technology (measured in one of three ways: cumulative patents in monolithic integration prior to going to Infinera, any patents in monolithic integration prior to going to Infinera, and more than two patents in monolithic integration prior to going to Infinera), and innovation capabilities in optoelectronics other than in the emerging technology (cumulative patenting in non-integrated technologies prior to going to Infinera). The variables and subscripts we use in the models that follow are defined in Table 3. We model the risk of a focus inventor going to Infinera as following:

$$
\begin{aligned}
h_{\text {inf }}(d)=h_{0}(d) & \exp \left(\beta_{1} \text { Asg }_{\text {onshore-not-Infinera }, d-1}+\beta_{2} \text { Asg } g_{\text {out-of-focus }, d-1}\right. \\
& \left.\quad+\beta_{3} N_{d-1}+\beta_{4} \text { Cinv }_{\text {mon }, d-1}+\beta_{5} \operatorname{Exp}_{\text {mon,d-1 }}+\beta_{6} \operatorname{Star}_{\text {mon }, d-1}+\beta_{7} \text { Cinv }_{\text {non-int }, d-1}\right)
\end{aligned}
$$

Importantly, these regression analyses are intended purely as descriptive statistics. While we have resumes for some of the inventors, as the interviews help reveal, across the inventor population there are innumerous characteristics that may be helping drive job and technology trajectory decisions which we are unable to observe in the regressions. 
Table 3 Variables and Subscripts (Individual Regressions)

\begin{tabular}{|c|c|c|c|}
\hline Subscript & Description & Purpose & Role \\
\hline D & Day & & Time \\
\hline $\mathbf{S}$ & $\begin{array}{l}\text { \{onshore-not-Infinera, out-of-focus, } \\
\text { offshore\} }\end{array}$ & Status of Assignee & $\begin{array}{l}\text { Organization } \\
\text { Category }\end{array}$ \\
\hline $\mathbf{A}$ & $\{$ monolithic, non-integrated $\}$ & Type of patent & $\begin{array}{l}\text { Patent } \\
\text { Category }\end{array}$ \\
\hline Variable & Description & Purpose & Role \\
\hline $\mathbf{h}_{\text {inf }}(d)$ & Risk of going to Infinera in day (d) & $\begin{array}{l}\text { Risk of joining the powerhouse of } \\
\text { the emerging technology }\end{array}$ & $\begin{array}{l}\text { Dependent } \\
\text { Variable }\end{array}$ \\
\hline $\operatorname{Asg}_{s, d-1}$ & $\begin{array}{l}\text { Fix effects of patent assignee's } \\
\text { status (s) for day (d-1) (d-1: one day } \\
\text { lag) }\end{array}$ & Status of current firms & $\begin{array}{l}\text { Independent } \\
\text { Variable }\end{array}$ \\
\hline $\mathbf{h}_{\mathrm{o}}(\mathrm{d})$ & $\begin{array}{l}\text { Baseline rate (being at offshoring } \\
\text { firm) in Cox going Infinera models }\end{array}$ & Baseline risk & \multirow{5}{*}{ 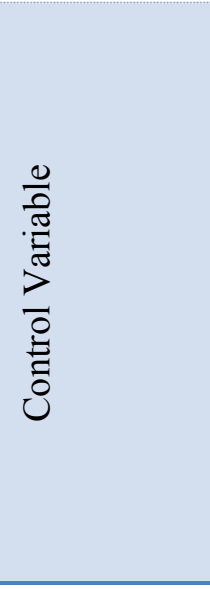 } \\
\hline $\mathbf{N}_{\mathrm{d}-1}$ & $\begin{array}{l}\text { Number of assignee changes for day } \\
\text { (d-1) (d-1: one day lag) }\end{array}$ & Inventor mobility & \\
\hline $\operatorname{Cinv}_{\mathrm{a}, \mathrm{d}-1}$ & $\begin{array}{l}\text { Inventor's cumulative patent count } \\
\text { in patenting of patent type (a) in day } \\
\text { (d-1) (d-1: one day lag) }\end{array}$ & \multirow{3}{*}{ Existing innovation capability } & \\
\hline $\operatorname{Exp}_{a, d-1}$ & $\begin{array}{l}\text { Inventor's experience in patenting } \\
\text { of patent type (a) in day (d-1) (d-1: } \\
\text { one day lag) }\end{array}$ & & \\
\hline Star $_{a, d-1}$ & $\begin{array}{l}\text { Inventor has patented more than } \\
\text { twice in patent type (a) in day (d-1) } \\
\text { (d-1: one day lag) }\end{array}$ & & \\
\hline
\end{tabular}

\section{Results}

\subsection{Firm Regression Results}

\subsubsection{Relationship between offshoring and innovation}

\subsubsection{Negative Binomial Model}

The regression results (Table 4) show that offshoring of both assembly and fabrication activities are associated with a decrease in patenting in monolithic integration. Controlling for firm revenue, firm R\&D spending, the burst of the telecommunications bubble, and the total integrated optoelectronic patent activity in the U.S., each additional year a firm has both assembly and fabrication activities offshore is associated with a 0.59 decrease in yearly monolithic patents. These results complement the economics found in Fuchs and Kirchain (2010), which show that manufacturing overseas reduces the economic viability of producing the emerging (monolithically integrated) technologies. These results build on Fuchs and Kirchain (2010), showing that the firms not only lose incentives for producing the emerging technology - they also reduce their innovation activities back home in that same technology. Notably, we only find a statistically significant relationship between offshoring and reducing innovation activities in 
monolithic integration if the firms move fabrication offshore - the manufacturing capabilities key to producing the monolithically integrated technology.

The regression results for the relationship between offshoring and innovation in technologies other than monolithic integration tell a different story. The offshoring of only assembly activities is not associated with a statistically significant change in monolithic integration patenting activities; however, it is associated with an increase in both hybrid integrated and non-integrated patenting. Controlling again for firm revenue, firm $R \& D$ spending, burst of the telecommunications bubble, and the total nonintegrated optoelectronic patenting in the U.S., each additional year a firm has only assembly activities offshore is associated with a 0.79 increase in yearly hybrid patents and with a 0.71 increase in yearly nonintegrated patents. The increase in hybrid patenting is not surprising - hybrid integration is a labor- and assembly-focused substitute for monolithic integration that lacks the performance (in particular, size) advantages of monolithic integration but also doesn't require as technologically-advanced skills and thus can more easily be performed in an overseas facility. The increase in non-integrated patenting is difficult to interpret without a greater understanding of the specific patents. We ran class and subclass analyses on these non-integrated patents and also read a random sampling from each class, but no clear firm- or industry-level technology directions were apparent within the grouping. One interpretation of the increase in non-integrated patenting is that it supports theories that offshoring (here, of assembly) enables a firm to save costs and thereby direct more resources toward higher-value-added activities (Baily and Farrell, 2004), (even if not to the emerging technology of monolithic integration). Importantly, however, with the exception of one sub-subclass (372/50.1), which seemed to belong with monolithic integration, ${ }^{23}$ the sample of non-integrated patents that we read seemed likely to be more incremental and process-oriented innovation activities.

Together, these results suggest that the opportunity to offshore earlier in the product life cycle may be shifting the timing and directional focus of the firms that offshore. Specifically, in offshoring fabrication and assembly firms may be slowing or abandoning innovation in the emerging technology (monolithic integration). Similar to Christensen's depiction of disruptive technologies (Christensen, 1997), the performance advantages (in particular, smaller size) of monolithic integration are not valued by the optoelectronic component manufacturers' existing customers in telecommunications as much as they are likely to be valued in other, larger markets (computing, sensing, biotechnology) in the longer term. Wide-spread offshoring in the industry may also be extending the life of prevailing (discrete) and intermediate (hybrid) technologies: move only assembly offshore is associated with an increase innovation in hybrid and other non-integrated areas (including innovation in more incremental and

\footnotetext{
${ }^{23}$ We ran a robustness analysis grouping this sub-subclass instead with monolithic integration and find the same results as in the main model.
} 
process-oriented innovations). These results build on past work by Vernon, which theorizes a shift overseas after product a standardized and focus has shifted to process innovation (Vernon, 1966). Instead, here, the shift overseas changes the relative profitability of two competing designs, and potentially extends the life of the incumbent technology during the product life cycle (Foster, 1986; Henderson et al., 1995; Rosenberg, 1976).

To assess the robustness of our regression results, we run several additional analyses. First, we explore the relationship between offshoring and innovation when each type of offshoring is instead measured as a "yes/no" (e.g. dummy) variable, instead of being measured as the number of years a firm has a particular type of facility offshore. The results of our previous models hold, except that the size of the effect of moving both assembly and fabrication offshore on monolithic integration increases (e.g. a larger negative coefficient), the burst of the telecom bubble in the model with monolithic integration as the dependent variable loses significance, and the relationship between offshoring and patenting in hybrid integration loses significance. Second, we explore whether the results of the negative binomial model hold if we only include firms that have at least one patent in monolithic integration in the observation period. Again, our results hold (including magnitude of the coefficients), except that the negative effect of moving only assembly offshore on monolithic integration patenting goes from being marginally significant to being significant at the $5 \%$ level, and the burst of the telecom bubble in the model with monolithic integration as the dependent variable loses significance. Third, keeping with our primary model measuring extent of offshoring, we control for Infinera. Infinera is an outlier in our firms because it never goes offshore and holds $32 \%$ of all of our focus firms' patents in monolithic integration. These two characteristics of Infinera may overly influence our model. Here, the results of our previous models hold, except that the size of the effect of moving both assembly and fabrication offshore on monolithic integration decreases slightly, and the burst of the telecom bubble loses significance. The remaining effects are similar, and the significance levels do not change. Fourth, we explore including firm fixed effects for all firms into our regression to control for individual firm strategies. Here, the results suggest that offshoring (of assembly or of both assembly and fabrication activities) is not associated with a statistically significant change in innovation. ${ }^{24}$ However, the number of observations per firm is very small; thus, these results should not be seen as conclusive. We also explored the analysis without the telecom bubble burst (which potentially could exacerbate sample size issues), and find similar results. It is worth noting that in both cases (with and without the bubble burst) many of the firm fixed effect coefficients are statistically significant and vary in magnitude and direction. This finding may imply that individual firms or distinct groups of firms may have divergent behavioral trends that are associated with their innovation trajectories.

\footnotetext{
${ }^{24}$ The offshoring coefficients keep their sign but lose statistical significance.
} 
Given the above-described results when adding firm fixed effects, we went back to the data to develop a descriptive understanding of the strategies of individual firms, and whether these strategies naturally fell into distinct groups. Whereas incompleteness of data in some control variables limited which observations we were able to include in our regression analyses, in the descriptive analyses we were not held to the same limitations. Leveraging the more extensive data available through the SEC filings and our firm surveys, we first created a descriptive write-up of each firm. (See Appendix 1.) Using methods common to case study analysis (Eisenhardt, 1989), we then unpacked the trajectories of groupings of firms to help inform our interpretation of the quantitative results. We found that our firms fell into one of five main categories: the "all-onshore strategists," the "all-offshore strategists", the "hedgers" (fabrication onshore, assembly offshore), the "late offshorers" (don't go offshore immediately after the burst of the telecommunications bubble in the first wave of firms, but instead go after 2005), and the "early exiters" (after the burst of the bubble, either are acquired or go out of business by 2004).

Having completed this descriptive analysis of the firms and their strategies, we then explored fixed effects associated with these five groupings of firm strategies. Unlike the firm fixed effects, where we suffered from small numbers of observations for some firms, the robustness analysis leveraging these strategy groupings is more statistically stable. In this analysis, we are - similar to firm fixed effects able to adjust for firm strategy, but now in addition we can see the (adjusted) association between each type of strategy and patenting. Our results for the relationship between number of years offshore and patenting (both for offshoring only assembly and for offshoring both assembly and fabrication) are broadly consistent in magnitude and significance to the primary model shown in Table 4. The inclusion of firm strategies results in a loss of significance for the telecom bubble burst. While we see no statistically significant relationship between firm strategy and monolithic patenting, we find, in keeping with our theory, a negative association between "all-onshore" and "late-offshore" strategies and nonintegrated patenting. Given the low counts in monolithic patenting, we are not surprised that it would be difficult for these patent counts to see an effect.

As with firm fixed effects, we also explored the analysis without the telecom bubble burst (which potentially could exacerbate sample size issues). With respect to the relationship between a firm's strategy and patenting (regardless of number of years offshore), once we remove the telecommunications bubble, all strategies except keeping all manufacturing onshore - specifically, being "all-offshore", a "hedger", or an "early exiter" - are associated with a decrease in monolithic patenting. Again, these results match our theory. As with the analysis that included the control for the telecommunication bubble, while the "all-onshore" and "late-offshore" groups do not have a statistically significant association with monolithic patenting, they have a negative association with non-integrated patenting. These results suggest that the firms with strategies that keep their fabrication onshore (either everything onshore, just 
fabrication, or not going offshore in the first wave immediately after the bubble burst) may be more likely to have fewer non-integrated patents, compared to firms with more aggressive offshoring strategies.

The above analyses only present correlations between number of years offshore and firms' quantity and direction of innovation. Building on the above strategy fixed effects, in section 4.3.2 below, we explore what type of firms are more likely to move offshore, and in particular whether firms with lower capabilities in monolithic integration (or other common traits) are more likely to move. This said, it is worth noting that given the economics shown in Fuchs and Kirchain (Fuchs and Kirchain, 2010), even if we were to find that the weakest firms in innovation (or monolithic innovation) are those most likely to move overseas, it may not matter for national innovation outcomes if the firms that stay in the U.S. to pursue the emerging, monolithically integrated technology cannot survive in the short term. As shown earlier in Figure 2, firms that move manufacturing overseas are able to produce the old, discrete technology in Developing East Asia at a significantly lower cost than they can produce either the emerging, monolithically integrated or the prevailing, discrete technology in the U.S. Thus, firms that move overseas and produce there the prevailing technology will be able to out cost-compete firms that stay in the U.S. and attempt to produce there the emerging technology until markets (such as the sensor or computing markets) are willing to pay for the added performance provided by the emerging technology.

Table 4 Negative Binomial Regressions on Focus Firms

\begin{tabular}{|c|c|c|c|}
\hline & Monolithic integrated & Hybrid integrated & Non-integrated \\
\hline $\begin{array}{l}\text { Assembly Only } \\
\text { Offshoring }_{y-1}\end{array}$ & $\begin{array}{l}-0.53 \\
(0.28)\end{array}$ & $\begin{array}{l}0.79 * * \\
(0.26)\end{array}$ & $\begin{array}{l}0.71 * * * \\
(0.18)\end{array}$ \\
\hline Both Offshoring $_{\mathrm{y}-1}$ & $\begin{array}{l}-0.59 * * * \\
(0.15)\end{array}$ & $\begin{array}{l}-0.009 \\
(0.09)\end{array}$ & $\begin{array}{l}-0.02 \\
(0.06)\end{array}$ \\
\hline Revenue $_{\mathrm{y}}$ & $\begin{array}{l}-4.6 e-11 \\
(1.7 e-10)\end{array}$ & $\begin{array}{l}1.9 \mathrm{e}-10 \\
(1.5 \mathrm{e}-10)\end{array}$ & $\begin{array}{l}2.4 \mathrm{e}-10 * \\
(1.0 \mathrm{e}-10)\end{array}$ \\
\hline R\&D Spending ${ }_{\mathrm{y}-1}$ & $\begin{array}{l}1.4 \mathrm{e}-09 . \\
(1.1 \mathrm{e}-09)\end{array}$ & $\begin{array}{l}-3.6 \mathrm{e}-10 \\
(1.3 \mathrm{e}-09)\end{array}$ & $\begin{array}{l}3.9 \mathrm{e}-10 \\
(7.1 \mathrm{e}-10)\end{array}$ \\
\hline U.S. Int. Patent ${ }_{\mathrm{y}}$ & $\begin{array}{l}0.002 \\
(0.005)\end{array}$ & $\begin{array}{l}0.03 * * * \\
(0.006)\end{array}$ & \\
\hline $\begin{array}{l}\text { U.S. Non-int. } \\
\text { Patent }_{y}\end{array}$ & & & $\begin{array}{l}7.6 \mathrm{e}-04 * * * \\
(1.2 \mathrm{e}-04)\end{array}$ \\
\hline Telecom bubble $_{\mathrm{y}-1}$ & $\begin{array}{l}0.92 * \\
(0.73)\end{array}$ & $\begin{array}{l}-0.89 \\
(0.59)\end{array}$ & $\begin{array}{l}-0.54 * * \\
(0.21)\end{array}$ \\
\hline Constant & $\begin{array}{l}-1.04 \\
(0.75)\end{array}$ & $\begin{array}{l}-4.26 * * * \\
(0.69)\end{array}$ & $\begin{array}{l}-1.09 \\
(0.61)\end{array}$ \\
\hline $\mathbf{N}=$ & 152 & 152 & 152 \\
\hline AIC & 325.21 & 245.71 & 1093.8 \\
\hline
\end{tabular}




\subsubsection{Cox Proportional Hazard Model}

In contrast to negative binomial models, a Cox proportional hazard model allows us to incorporate varying patent rates over a year and that a firm's number of patents across years may be correlated. The results of the patent hazard models (Table 5) suggest that offshoring both assembly and fabrication activities is associated with a decreased risk of patenting in monolithic integration. Controlling for offshoring only assembly activities, firm revenue, and firm $R \& D$ spending, each additional year a firm has both assembly and fabrication facilities offshore is associated with a marginally significant decrease of $26 \%$ of the risk for firms to file a monolithic patent. These results, while only marginally significant, match the economics found in Fuchs and Kirchain (Fuchs and Kirchain, 2010), which show that manufacturing offshore reduces firms' incentives for developing the emerging monolithic products. They extend these past results by suggesting that in following these economics, firms not only stop producing but also reduce their innovation in the emerging technology. Again, the relationship between offshoring and reduced risk of innovation in monolithic integration is only found once the firms move fabrication offshore.

We also use Cox proportional hazards regression to model the relationship between offshoring and innovation in the prevailing non-integrated technologies. Like with the negative binomial model, we find the opposite results for non-integrated than for the monolithically integrated technology. Controlling for offshoring only assembly activities, firm revenue, and firm R\&D spending, each additional year a firm has both assembly and fabrication facilities offshore is associated with an increased risk of $27 \%$ for firms to file a non-integrated patent. One interpretation of these results is that they support economic theories that offshoring enables a firm to save costs and thereby direct more resources toward higher-value-added activities (Baily and Farrell, 2004), (even if not to the emerging technology of monolithic integration.) As discussed in the previous section, however, the sample of non-integrated patents that we read seemed likely to be more incremental and process-oriented innovation activities.

In contrast with the negative binomial model results, in the hazard models moving both assembly and fabrication offshore (not moving only assembly offshoring) is associated with a statistically significant increase in a firm's risk of patenting in non-integration. The underlying data reveals that one firm, Agilent - which moves both assembly and fabrication offshore in 1999, has a disproportionately large spike in its non-integrated patenting (compared to upward or downward patenting rates of other firms) at the beginning of its offshoring period. After this initial boost, however, Agilent's non-integrated patenting dramatically declines for the duration of our observation period. This spike in Agilent's innovation activities combined with Agilent's consistently larger numbers of patents may be overly 
influencing the results. ${ }^{25}$ One potential explanation for this brief spike is that they may have been patenting earlier invented technologies in preparation for losing employees associated with offshoring.

Table 5 Cox Patent Rate Models on Rate of Patenting in Monolithic and Non-Integrated Technologies

\begin{tabular}{|c|c|c|c|}
\hline & Monolithic & Hybrid & Non-Integrated \\
\hline \multirow{2}{*}{$\begin{array}{l}\text { Assembly Only } \\
\text { Offshoring }_{\mathbf{y}(d)-1}\end{array}$} & 0.29 & 1.32 & 1.57 \\
\hline & (1.04) & $(0.31)$ & $(0.29)$ \\
\hline \multirow{2}{*}{ Both Offshoring $_{y(d)-1}$} & 0.74 & 1.03 & $1.27 *$ \\
\hline & $(0.18)$ & $(0.07)$ & $(0.11)$ \\
\hline \multirow{2}{*}{ Revenue $_{y(d)}$} & $0.59 * * *$ & 1.09 & 1.14 \\
\hline & $(0.12)$ & $(0.06)$ & $(0.15)$ \\
\hline \multirow{2}{*}{ R\&D Spending $_{\mathrm{y}(\mathrm{d})-1}$} & $2.03 * * *$ & 1.07 & 1.26 \\
\hline & $(0.18)$ & $(0.12)$ & $(0.15)$ \\
\hline U.S. Int. Patent $_{\mathbf{y}(\mathrm{d})}$ & $\begin{array}{l}1.01 \\
(0.009)\end{array}$ & $\begin{array}{l}1.03 * * * \\
(0.008)\end{array}$ & \\
\hline \multicolumn{2}{|l|}{ U.S. Non-int. Patent } & & $\begin{array}{l}1.001 * * * \\
(1.7 \mathrm{e}-05)\end{array}$ \\
\hline Telecom bubble $_{d-365}$ & $\begin{array}{l}0.22 \\
(0.84)\end{array}$ & $\begin{array}{l}0.08 * * \\
(0.93)\end{array}$ & $\begin{array}{l}0.53 * \\
(0.27)\end{array}$ \\
\hline $\mathbf{N}=$ & 122 & 85 & 2964 \\
\hline \multicolumn{4}{|c|}{$\begin{array}{l}\text { All coefficients are in hazard ratios. Note that coefficients less than } 1 \text { are equivalent to negative associations. } \\
\text { All regressions are repeated events clustered by firm with robust standard errors (in parentheses) } \\
\text { Signif. codes: } \star^{* * * *} p<0.001 ;{ }^{\prime * *} p<0.01 ;{ }^{*} ’ p<0.05 ; \because p<0.1\end{array}$} \\
\hline
\end{tabular}

Together, these results again suggest that the opportunity to offshore at a stage in the product life cycle when there are competing product technologies may shift the timing and direction of technological activities in the firms that offshore. In contrast to Vernon, who imagines a shift overseas after a product is standardized and focus has shifted to process innovation (Vernon, 1966), here, the shift overseas changes the relative profitability of two competing designs mid-stream during the competition: Offshoring is associated with a slowing of the emerging, and potentially disruptive technology (Christensen, 1997) and potentially extending the life of the incumbent technology during the product life cycle (Foster, 1986; Henderson et al., 1995; Rosenberg, 1976).

\subsubsection{Relationship between innovation capability and risk of offshoring}

Our Cox proportional hazard regression models of the risk of going offshore indicate that cumulative non-integrated patenting (the innovation capability of non-integrated design) is marginally associated with an increase in the probability of offshoring any type of facility. Controlling for firms' cumulative monolithic and hybrid patenting, firm revenue, firm R\&D spending, the burst of the telecommunications bubble, and field-wide trends in integration and non-integration patenting; each additional cumulative non-integrated patent is associated with a $1 \%$ increase in the risk of moving any

\footnotetext{
${ }^{25}$ When running the proportional hazards regression without Agilent, our results become similar to those reported in the negative binomial, where the relationship between moving only assembly offshore and non-integrated patenting is positive and significant and the relationship between moving both offshore and non-integrated patenting is non-significant, but has a negative coefficient.
} 
facility offshore (marginally significant). We also find a marginally significant positive correlation between the burst of the telecommunications bubble and offshoring.

Table 6 Cox proportional hazard regression results on the risk of moving any facility offshore

\begin{tabular}{|c|c|}
\hline & Rate of offshoring any type of facility \\
\hline Cumulative monolithic patent $\mathrm{y}_{\mathrm{y}}$ & $\begin{array}{l}0.94 \\
(0.05)\end{array}$ \\
\hline Cumulative hybrid patent y $_{\text {}}$ & $\begin{array}{l}1.22 \\
(0.27)\end{array}$ \\
\hline Cumulative non-integrated patent $t_{y}$ & $\begin{array}{l}1.01 \\
(0.006)\end{array}$ \\
\hline Revenue $_{y}$ & $\begin{array}{l}1.39 \\
(0.36)\end{array}$ \\
\hline R\&D spending $\mathrm{y}$ & $\begin{array}{l}0.64 \\
(0.44)\end{array}$ \\
\hline U.S. Int. Patent ${ }_{\mathrm{y}}$ & $\begin{array}{l}0.98 \\
(0.03)\end{array}$ \\
\hline U.S. Non-int. Patent $y_{y}$ & $\begin{array}{l}1.00 \\
(7 e-4)\end{array}$ \\
\hline Telecom bubble y $_{\text {}}$ & $\begin{array}{l}22.06 \\
(1.82)\end{array}$ \\
\hline ( & 131 \\
\hline
\end{tabular}

These Cox proportional hazard results for probability of offshoring do not clearly support the theory that firms that have low capability in patenting (monolithic, hybrid and non-integrated) would have a higher probability to go offshore. Indeed, the positive relationship between non-integrated patenting and going offshore may suggest that firms with a breadth of capabilities perceive that they have greater competencies to leverage in going offshore. Our results also do not support a theory that firms that were weak in monolithic integration would be more likely to go offshore. Table 7 below shows correlations between the three different types of patenting. The results show that a firm's monolithic, hybrid and nonintegrated cumulative patenting are all positively correlated with each other. These results suggest that a firm that has a high innovation capability (large cumulative patents) in the non-integrated design is likely to also have high innovation capability in monolithic and hybrid designs.

To assess the robustness of the above results, we also model the risk of a firm moving only assembly and of moving both assembly and fabrication offshore. In addition, we explore the relationship between yearly patenting rates (instead of cumulative patent numbers) and the risk of offshoring for all three definitions of offshoring. ${ }^{26}$ Similar to the cumulative results, the results of the offshoring hazard models with yearly patenting rates show that yearly non-integrated patenting is associated with an

\footnotetext{
${ }^{26}$ To recall, our three definitions of offshoring for the offshoring hazard models are any type of facility offshore, offshoring only assembly, or offshoring both assembly and fabrication facilities.
} 
increase in the risk of any type of offshoring (significant at the 0.05 level) and an increase in the risk of moving both assembly and fabrication offshore (marginally significant). None of the other models found a statistically significant relationship between firm's patenting and the rate of offshoring. These results suggest that a firm's innovation capability is either not associated with going offshore or at best positively associated.

Table 7 Correlation between each type of cumulative patents

\begin{tabular}{llll}
\hline & $\begin{array}{l}\text { Cumulative } \\
\text { monolithic }\end{array}$ & $\begin{array}{l}\text { Cumulative } \\
\text { hybrid }\end{array}$ & $\begin{array}{l}\text { Cumulative } \\
\text { non-integrated }\end{array}$ \\
\hline $\begin{array}{l}\text { Cumulative monolithic } \\
\text { Cumulative hybrid }\end{array}$ & 1 & 0.435 & 0.398 \\
$\begin{array}{l}\text { Cumulative } \\
\text { non-integrated }\end{array}$ & - & 1 & 0.621 \\
\hline
\end{tabular}

\subsection{Inventor Results}

While firms that offshore may reduce their innovation efforts in monolithic integration, inventors need not take the same trajectory as firms. Table 8 shows the percentage of (or probability that) inventors within our focus "strong" integration group versus each of our control groups take particular actions. The actions we observe are as follows: (1) eventually leave the focus firm, (2) conditional on leaving the focus firm leave to an onshore firm (if at an offshoring firm) versus to an out-of-focus firm, and (3) conditional on leaving and to what type of firm they go, keep patenting in monolithic integration. ${ }^{27}$ We use t-tests to assess whether the observed differences between groups are statistically significant. (See Table 9.)

\subsubsection{Do the inventors at the offshoring firms with strong capabilities in monolithic} integration leave, and keep innovating in the emerging technology at other institutions?

On average, $43 \%$ of inventors with strong capabilities in monolithic integration (and who patent at the focus firms in monolithic integration) eventually leave. There is no statistically significant difference in the leave rates of these inventors whether they are at an offshoring firm or a non-offshoring firm. In contrast, on average only $17 \%$ of inventors with only one or two patents in integration (our "dabblers") or with no patents in integration eventually leave their firms. ${ }^{28}$

\footnotetext{
${ }^{27}$ Note: the total number of "focus" integrated inventors shown in Table 8 is 98 instead of 106 due to, given limited space, not including in the table two groups of inventors: seven inventors with three or more integrated patents who have monolithic experience only post being in our focus firms (and no monolithic patents prior to or at our focus firms) and one inventor (out of 3388 inventors who ever patent at our focus firms) that didn't fit into our classification system. The seven inventors (the first group) had only non-integrated patents at offshoring firms and then go to an onshore firm and patent in monolithic (6 go to Infinera and one goes to Xponent). We discuss the six inventors that go to Infinera in greater detail in section5.2.2. The one inventor who didn't fit our classification system currently works at an offshoring firm (Neophotonics) and has no patents at that firm but had monolithic patents at Lightwave (an on-shore firm acquired by Neophotonics) and in one out-of-focus firm (pre Lightwave) prior to going to Neophotonics. The fact that this inventor goes from an onshore firm to an offshore firm (in this case, due to a acquisition) excludes him from fitting one of the categories in the table.

${ }^{28}$ Inventors with no patents in integration have a slightly lower probability to leave if they are at an offshoring firm, but otherwise there are no statistically significant differences between the two control groups
} 
Of the inventors with strong innovation capabilities in integration who have patented at the focus firm in monolithic integration and eventually leave, almost all of them (94\%) leave to firms outside the optoelectronic component manufacturing industry for telecommunications (e.g. leave to "out-of-focus" firms). (This statistic is also similar for our control group — of the inventors at our focus firms with no integration patents who leave, more than $99 \%$ of them go to out-of-focus firms.) In contrast to past literature on the persistence of inventors in their area of expertise (Furman et al., 2012; Garud and Rappa, 1995), of the inventors with strong monolithic integration capabilities at our offshoring firms who eventually leave, only $21 \%$ of them patent in monolithic integration after leaving. Thus, of the inventors who had been patenting in monolithic integration at the offshoring firms and leave the industry (to out-offocus firms) the majority of them end up not pushing forward efforts in monolithic integration in their new locations. ${ }^{29}$ Notably, these results do not indicate that monolithic integration activities are not continued by anyone after they are abandoned by the offshoring firms, just that the majority of the inventors previously patenting in monolithic at the offshoring firms are not the ones to do it.

With respect to continuing innovation in the emerging technology in the industry, two points stand out in the data. First, of the $40 \%$ of inventors with strong capabilities in monolithic integration who eventually leave an offshoring firm, $10 \%$ (two) of these inventors ${ }^{30}$ go to an onshore firm, and both of them continue patenting in monolithic integration. That onshore firm is Infinera. Second, $70 \%$ of inventors with strong capabilities in monolithic integration, who have prior experience in monolithic integration but without any patents in monolithic integration at our focus offshoring firms eventually leave. Of those who eventually leave the offshoring firms $43 \%$ (three) ${ }^{31}$ go to a single onshore firm, and all of them re-start patenting in monolithic integration at that onshore firm. Again, this onshore firm is Infinera. Particularly noteworthy in the above findings is that inventors with prior strong emerging technology capabilities that were not using those capabilities at the focus firms are both more likely to leave, and more likely to go to an onshore firm (specifically, Infinera) where they patent in the emerging technology. (The latter point is marginally significant on a very small sample size.) Given the regional locations of these inventors, these inventors would not be affected in their states by strongly enforced non-compete regulations. This said, other incentives, such as the recipient company not wanting to risk patent or knowledge infringement challenges from recent employers (Agarwal et al., 2009), might be driving these differences.

\footnotetext{
${ }^{29}$ As an aside, a slightly higher percentage of the equivalent inventors from never offshore firms patent in monolithic integration after leaving $-43 \%$. This difference is marginally significant, despite the low sample size.

${ }^{30}$ These two inventors are Mark Missey, who left JDSU with Infinera founder David Welch, and Andrew Denati, who David Welch recruited from Agere. (See quote in section 5.2.2 from David Welch.)

${ }^{31}$ These three are David Welch, Infinera's co-founder and President, Fred Kish, who David Welch recruited from Agilent and who becomes Infinera's Senior Vice President of the Optical Integrated Circuit Group, and Charles Hoyner, who David Welch recruited from TriQuint. (See quote in section 5.2.2 from David Welch.)
} 
Table 8 Comparison between different groups of inventors

\begin{tabular}{|c|c|c|c|c|c|c|c|c|c|c|c|c|c|c|}
\hline & \multicolumn{6}{|c|}{$\begin{array}{l}\text { Focus Integrated Inventors } \\
\qquad(>2 \text { Int. Patents) }\end{array}$} & \multicolumn{6}{|c|}{$\begin{array}{l}\text { Remaining Integrated Inventors } \\
\text { (1 or } 2 \text { Int. Patents) }\end{array}$} & \multirow{2}{*}{\multicolumn{2}{|c|}{$\begin{array}{l}\text { No Integrated } \\
\text { Patents }\end{array}$}} \\
\hline & \multicolumn{4}{|c|}{ Patent in Monolithic } & \multicolumn{2}{|c|}{ Patent in Hybrid } & \multicolumn{4}{|c|}{ Patent in Monolithic } & \multicolumn{2}{|c|}{ Patent in Hybrid } & & \\
\hline & \multicolumn{2}{|c|}{ @ Focus firms } & \multicolumn{2}{|c|}{ Pre-focus firm } & \multicolumn{2}{|c|}{ (a) Focus firms } & \multicolumn{2}{|c|}{ (a) Focus firms } & \multicolumn{2}{|c|}{ Pre-focus firm } & \multicolumn{2}{|c|}{ (a) Focus firms } & & \\
\hline & \multicolumn{2}{|c|}{81} & \multicolumn{2}{|c|}{10} & \multicolumn{2}{|c|}{7} & \multicolumn{2}{|c|}{228} & \multicolumn{2}{|c|}{8} & \multicolumn{2}{|c|}{147} & \multicolumn{2}{|c|}{2907} \\
\hline & $\begin{array}{c}52 \\
\text { Ever } \\
\text { offshore }\end{array}$ & $\begin{array}{c}29 \\
\text { Never } \\
\text { offshore }\end{array}$ & $\begin{array}{c}10 \\
\text { Ever } \\
\text { Offshore }\end{array}$ & $\begin{array}{c}0 \\
\text { Never } \\
\text { Offshore }\end{array}$ & $\begin{array}{c}6 \\
\text { Ever } \\
\text { Offshore }\end{array}$ & $\begin{array}{c}1 \\
\text { Never } \\
\text { Offshore }\end{array}$ & $\begin{array}{c}193 \\
\text { Ever } \\
\text { offshore }\end{array}$ & $\begin{array}{c}35 \\
\text { Never } \\
\text { offshore }\end{array}$ & $\begin{array}{c}8 \\
\text { Ever } \\
\text { Offshore }\end{array}$ & $\begin{array}{c}0 \\
\text { Never } \\
\text { Offshore }\end{array}$ & $\begin{array}{c}134 \\
\text { Ever } \\
\text { Offshore }\end{array}$ & $\begin{array}{c}13 \\
\text { Never } \\
\text { Offshore }\end{array}$ & $\begin{array}{c}2685 \\
\text { Ever } \\
\text { offshore }\end{array}$ & $\begin{array}{c}222 \\
\text { Never } \\
\text { offshore }\end{array}$ \\
\hline $\begin{array}{l}\text { Eventually } \\
\text { Leave }\end{array}$ & $\begin{array}{l}40 \% \\
(21)\end{array}$ & $\begin{array}{l}48 \% \\
(14)\end{array}$ & $\begin{array}{l}70 \% \\
(7)\end{array}$ & $0 \%$ & $33 \%$ & 0 & $\begin{array}{l}18 \% \\
(34)\end{array}$ & $\begin{array}{l}17 \% \\
(6)\end{array}$ & $\begin{array}{l}25 \% \\
(2)\end{array}$ & 0 & $16 \%$ & $\begin{array}{r}8 \% \\
(1)\end{array}$ & $16 \%$ & $23 \%$ \\
\hline $\begin{array}{l}\text { To } \\
\text { On-shore }\end{array}$ & $\begin{array}{l}10 \% \\
(2)\end{array}$ & NA & $\begin{array}{l}43 \% \\
(3)\end{array}$ & NA & $\begin{array}{c}50 \% \\
(1)\end{array}$ & NA & $0 \%$ & NA & $\begin{array}{l}50 \% \\
(1)\end{array}$ & NA & $0 \%$ & NA & $\begin{array}{l}0.23 \% \\
\text { (1) }\end{array}$ & NA \\
\hline $\begin{array}{l}\text { Patent in } \\
\text { Mon. } \\
\text { after } \\
\text { Leaving }\end{array}$ & $100 \%$ & NA & $100 \%$ & NA & $100 \%$ & NA & $0 \%$ & NA & $\begin{array}{l}100 \% \\
(1)\end{array}$ & NA & $0 \%$ & NA & NA & NA \\
\hline $\begin{array}{l}\text { To } \\
\text { Out-of- } \\
\text { Focus }\end{array}$ & $\begin{array}{l}90 \% \\
(19)\end{array}$ & $100 \%$ & $\begin{array}{l}57 \% \\
(4)\end{array}$ & $0 \%$ & $50 \%$ & $0 \%$ & $\begin{array}{l}100 \% \\
(34)\end{array}$ & $\begin{array}{l}100 \% \\
(6)\end{array}$ & $\begin{array}{l}50 \% \\
(1)\end{array}$ & $0 \%$ & $100 \%$ & $100 \%$ & $99 \%$ & $100 \%$ \\
\hline $\begin{array}{l}\text { Patent in } \\
\text { Mon. } \\
\text { after } \\
\text { Leaving }\end{array}$ & $\begin{array}{l}21 \% \\
(4)\end{array}$ & $\begin{array}{c}43 \% \\
(6)\end{array}$ & $\begin{array}{c}25 \% \\
(1)\end{array}$ & $0 \%$ & $0 \%$ & $0 \%$ & $\begin{array}{l}6 \% \\
(2)\end{array}$ & $0 \%$ & $0 \%$ & $0 \%$ & $0 \%$ & $0 \%$ & NA & NA \\
\hline
\end{tabular}


Table 9 T-test between different groups of inventors' ratios of eventually leaving

\begin{tabular}{|c|c|c|c|c|c|c|c|c|c|c|c|c|c|c|c|c|c|}
\hline & 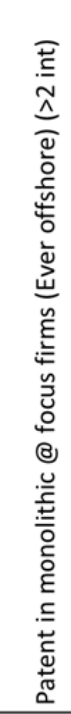 & 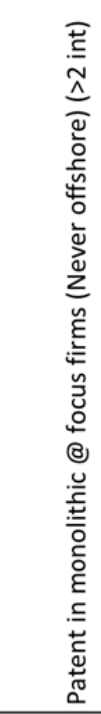 & 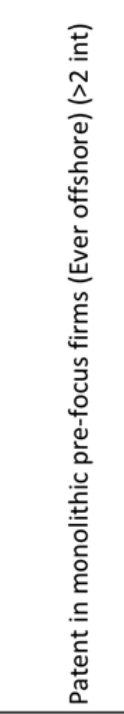 & 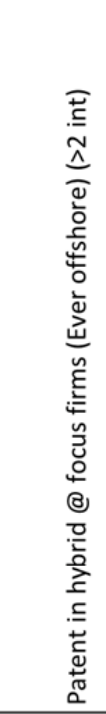 & 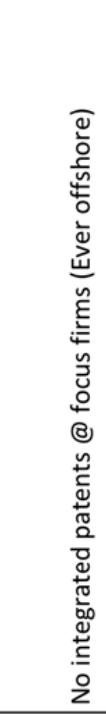 & & 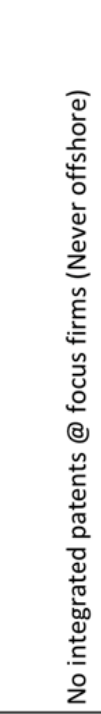 & & 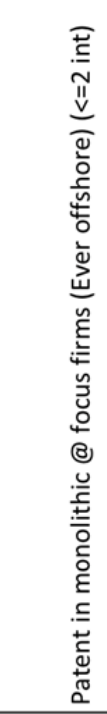 & & 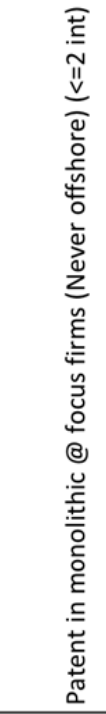 & & 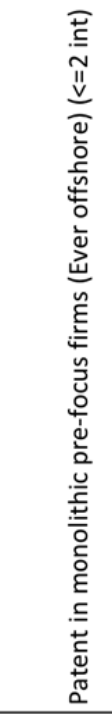 & 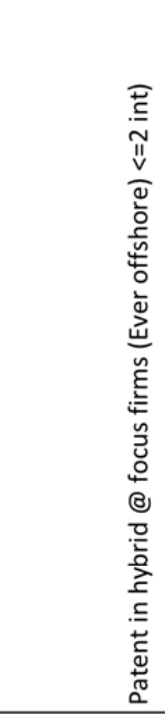 & & 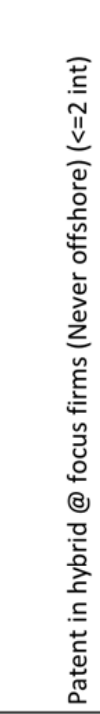 & \\
\hline Patent in monolithic @ focus firms (Ever offshore) (>2 int) & - & 0.2443 & $0.0328^{*}$ & 0.3661 & 0.0002 & *** & 0.0108 & * & 0.0015 & ** & 0.0077 & ** & 0.1871 & 0.0008 & *** & 0.0012 & ** \\
\hline Patent in monolithic @ focus firms (Never offshore) (>2 int) & - & - & 0.1044 & 0.2433 & 0.0003 & $* * *$ & 0.0053 & $* *$ & 0.0011 & $* *$ & 0.0038 & $* *$ & 0.1035 & 0.0007 & $* * *$ & 0.0009 & $* * *$ \\
\hline Patent in monolithic pre-focus firms (Ever offshore) ( $>2 \mathrm{int}$ ) & - & - & - & 0.0724 & 0.0001 & $* * *$ & 0.0008 & $* * *$ & 0.0003 & $* * *$ & 0.0008 & $* * *$ & 0.0238 & 0.0002 & $* * *$ & 0.0005 & $* * *$ \\
\hline Patent in hybrid @ focus firms (Ever offshore) (>2 int) & - & - & - & - & 0.1881 & & 0.3034 & & 0.2201 & & 0.2167 & & 0.3749 & 0.1919 & & 0.1205 & \\
\hline No integrated patents @ focus firms (Ever offshore) & - & - & - & - & - & & 0.0081 & $* *$ & 0.2418 & & 0.4378 & & 0.2785 & 0.5000 & & 0.1449 & \\
\hline No integrated patents @ focus firms (Never offshore) & - & - & - & - & - & & - & & 0.1033 & & 0.1944 & & 0.4489 & 0.0500 & $*$ & 0.0316 & $*$ \\
\hline Patent in monolithic @ focus firms (Ever offshore) (<=2 int) & - & - & - & - & - & & - & & - & & 0.4427 & & 0.3266 & 0.3173 & & 0.1068 & \\
\hline Patent in monolithic @ focus firms (Never offshore) ( $<=2$ int) & - & - & - & - & - & & - & & - & & - & & 0.3159 & 0.4440 & & 0.1827 & \\
\hline Patent in monolithic pre-focus firms (Ever offshore) ( $<=2$ int) & - & - & - & - & - & & - & & - & & - & & - & 0.2829 & & 0.1654 & \\
\hline Patent in hybrid @ focus firms (Ever offshore) <=2 int) & - & - & - & - & - & & - & & - & & - & & - & - & & 0.1742 & \\
\hline Patent in hybrid @ focus firms (Never offshore) ( $<=2$ int) & - & - & - & - & - & & - & & - & & - & & - & - & & - & \\
\hline
\end{tabular}

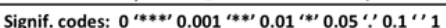




\subsubsection{The Inventors that Go to Infinera}

As shown in our firm analysis, Infinera - which holds $21 \%$ of integrated patents (monolithic and hybrid) within our focus firms and $32 \%$ of monolithic integration patents within our focus firms - plays a critical role after its founding in $2000^{32}$ in the emerging technology innovation. Our findings at the individual level shows $22 \%$ of our 106 strong integration inventors (three or more patents in integration) and $83 \%$ of our inventors with more than nine integrated patents work at some point at Infinera. To understand better what led to the creation of such a powerhouse in integration, we examine the trajectories of inventors who have ever worked at Infinera, and try to unpack Infinera's potential strategy in hiring these inventors (Table 10 and Table 11).

Table 10 Cox proportional hazard regression results on the risk of a focus inventor going to Infinera

\begin{tabular}{|c|c|c|c|}
\hline \multirow[b]{2}{*}{ Onshore-Not-Infinera $a_{d-1}$} & \multicolumn{3}{|c|}{ Risk of going to Infinera } \\
\hline & $\begin{array}{l}0.101 * \\
(1.092)\end{array}$ & $\begin{array}{l}0.098 * \\
(1.085)\end{array}$ & $\begin{array}{l}0.098 * \\
(1.086)\end{array}$ \\
\hline Out-of-Focus Firm $_{d-1}$ & $\begin{array}{l}0.314 * \\
(0.569)\end{array}$ & $\begin{array}{l}0.309 * \\
(0.565)\end{array}$ & $\begin{array}{l}0.340 \\
(0.553)\end{array}$ \\
\hline Number of Assignee Changes $_{d-1}$ & $\begin{array}{l}1.152 \\
(0.092)\end{array}$ & $\begin{array}{l}1.139 \\
(0.089)\end{array}$ & $\begin{array}{l}1.145 \\
(0.089)\end{array}$ \\
\hline 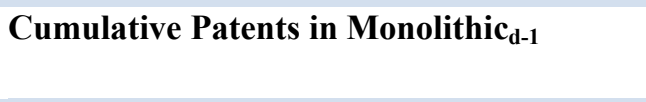 & $\begin{array}{l}0.699 \\
(0.218)\end{array}$ & & \\
\hline Patenting Exp. in Monolithic $_{\mathrm{d}-1}$ & & $\begin{array}{l}0.640 \\
(0.535)\end{array}$ & \\
\hline Star in Monolithic $_{\mathrm{d}-1}$ & & & $\begin{array}{l}0.407 \\
(0.814)\end{array}$ \\
\hline Cumulative Patents in Non-Intergrated $_{d-1}$ & $\begin{array}{l}0.996 \\
(0.019)\end{array}$ & $\begin{array}{l}0.990 \\
(0.019)\end{array}$ & $\begin{array}{l}0.991 \\
(0.019)\end{array}$ \\
\hline $\mathbf{N}$ & 426288 & & \\
\hline AIC & 125.5 & 128.3 & 127.5 \\
\hline $\begin{array}{l}\text { All coefficients are in hazard ratios. We include stand } \\
\text { Signif. codes: } 0{ }^{* * *}, 0.001{ }^{* *}, 0.01{ }^{*}, 0.05 \cdot{ }^{\prime}, 0.1 \text { ' }\end{array}$ & $d$ errors in & & \\
\hline
\end{tabular}

As can be seen in Table 10 and Table 11, Infinera hires its inventors predominantly from the offshoring firms: More than half (52\%) of the emerging technology (monolithic integration) inventors at Infinera worked previously at one of our offshoring firms. An inventor at an onshore firm in the industry other than Infinera has a 90\% lower risk of going to Infinera than an inventor at an offshoring firm, and an inventor at one point in time in the industry but now at a firm outside the industry (e.g. at an out-offocus firm) has a 66-70\% lower risk of going to Infinera than an inventor at an offshoring firm. (See Table 10. $)^{33}$ All of the inventors who worked at our offshoring firms before going to Infinera left the

\footnotetext{
${ }^{32}$ Infinera was founded in stealth mode in 2000 under the name Zepton Networks.

${ }^{33}$ The results reported here are intended purely as descriptive statistics of correlations between variables. As the interviews help reveal, across the inventor population there are innumerous characteristics that may be helping drive job and technology trajectory decisions which we are unable to observe in the regressions.
} 
Table 11 The Movement of Inventors Who Work at Some Point at Infinera

\begin{tabular}{|c|c|c|c|c|c|c|}
\hline $\begin{array}{l}\text { Monolithic Inventors } \\
\text { at Infinera }\end{array}$ & $\begin{array}{l}\text { Firm pre- } \\
\text { Infinera }\end{array}$ & $\begin{array}{l}\text { Headquarters } \\
\text { (state) }\end{array}$ & $\begin{array}{l}\text { Leave after firm } \\
\text { offshore (years) }\end{array}$ & $\begin{array}{l}\text { Arrival at } \\
\text { Infinera, }{ }^{34}\end{array}$ & $\begin{array}{l}\text { Firm post } \\
\text { Infinera }\end{array}$ & $\begin{array}{l}\text { Depart } \\
\text { Infinera }\end{array}$ \\
\hline $\begin{array}{l}\text { Drew Perkins } \\
\text { (Founder) }\end{array}$ & (NA) & (NA) & (NA) & 2001 & (NA) & (NA) \\
\hline $\begin{array}{l}\text { David F. Welch } \\
\text { (Founder) }\end{array}$ & JDSU & $\mathrm{CA}$ & 2 & 2001 & (NA) & (NA) \\
\hline Frank H. Peters & Avago & CA & 2 & 2001 & $\begin{array}{l}\text { Tyndall National } \\
\text { Institute }\end{array}$ & 2004 \\
\hline Richard P. Schneider & Avago & CA & 2 & 2001 & (NA) & (NA) \\
\hline $\begin{array}{l}\text { Stephen Gregory } \\
\text { Grubb } \dagger\end{array}$ & Corvis & $\mathrm{MD} \ddagger$ & (NA) & 2001 & (NA) & (NA) \\
\hline $\begin{array}{l}\text { Matthew L. Mitchell } \\
\dagger\end{array}$ & Corvis $\$$ & $\mathrm{MD} \ddagger$ & (NA) & 2001 & (NA) & (NA) \\
\hline Charles H. Hoyner & TriQuint & OR & 1 & 2002 & (NA) & (NA) \\
\hline $\begin{array}{l}\text { Radhakrishnan L. } \\
\text { Nagarajan }\end{array}$ & JDSU & $\mathrm{CA}$ & 2 & 2002 & (NA) & (NA) \\
\hline Mark J. Missey & JDSU & $\mathrm{CA}$ & 2 & 2002 & (NA) & (NA) \\
\hline Vincent G. Dominc & JDSU & $\mathrm{CA}$ & 2 & 2002 & (NA) & (NA) \\
\hline Atual Mathur & JDSU & $\mathrm{CA}$ & 2 & 2002 & (NA) & (NA) \\
\hline Andrew Dentai & Agere & PA & 2 & 2002 & (NA) & (NA) \\
\hline Fred Kish Jr. & Agilent & CA & 3 & 2002 & (NA) & (NA) \\
\hline Alan C. Nilsson $\dagger$ & $\begin{array}{l}\text { Harmonic } \\
\text { Lightwave }\end{array}$ & $\mathrm{CA}$ & (NA) & 2002 & (NA) & (NA) \\
\hline Jonas Webjorn $\dagger$ & Intel & CA & (NA) & 2002 & (NA) & (NA) \\
\hline Robert B. Taylor $\dagger$ & (NA) & (NA) & (NA) & 2002 & (NA) & (NA) \\
\hline Ting-Kuang Chiang $\dagger$ & (NA) & (NA) & (NA) & 2002 & (NA) & (NA) \\
\hline Brent Little & MIT & MA & (NA) & 2002 & (NA) & (NA) \\
\hline Mehrda Ziari & JDSU & $\mathrm{CA}$ & 3 & 2003 & (NA) & (NA) \\
\hline John Hryniewicz & $\begin{array}{l}\text { Little } \\
\text { Optics } \$\end{array}$ & $\mathrm{MD} \ddagger$ & (NA) & 2005 & (NA) & (NA) \\
\hline Wei Chen & Avanex & CA & 4 & 2007 & (NA) & (NA) \\
\hline David Gill & $\begin{array}{l}\text { Little } \\
\text { Optics } \ddagger\end{array}$ & $\mathrm{MD} \ddagger$ & (NA) & 2007 & (NA) & (NA) \\
\hline Wenlu Chen & (NA) & (NA) & (NA) & 2007 & (NA) & (NA) \\
\hline \multicolumn{7}{|c|}{$\begin{array}{l}\text { Hever worked at offshoring firms } \\
\text { In 2006, Infinera took over Corvis’s all-optical switch product line, including licensing the intellectual property rights to it, and } \\
\text { gaining } 40 \text { Broadwing employees that had been part of the Corvis business (Corvis changed its name to Broadwing in } 2004 \text { after } \\
\text { acquiring the Broadwing in 2003, however existing patents kept the Corvis name); Little Optics was acquired by Infinera in } 2007 \\
\text { (NA) Not applicable. }\end{array}$} \\
\hline
\end{tabular}

offshoring firm to go to Infinera one to four years after the firm moved offshore ${ }^{35}$. While $42 \%$ of these inventors had patented in the emerging technology prior to going to Infinera (two of these inventors had

\footnotetext{
${ }^{34}$ The time shows when the inventor had his/her first patent at Infinera (based on USPTO database) or when he/she entered Infinera (if his/her resume is available).

${ }^{35}$ Six of the 16 Infinera inventors come from JDSU, two from Avago, two from Corvis, one from TriQuint, one from Agilent, one from Intel, one from Harmonic Lightwaves, and two start their patenting careers at Infinera.
} 
patented in monolithic integration at the offshoring firm, and another three of these inventors had patented in monolithic integration prior to going to the offshoring firm), a full $58 \%$ of the inventors have their first patent in the emerging technology only after arriving at Infinera. As can be seen in Table 11, several inventors who worked together in the same firms - particularly JDSU and Avago (previously Agilent) move together to Infinera. In the case of JDSU, the inventors follow David Welch - one of Infinera's three founders. David Welch originally worked at SDL, which was acquired by JDSU in 2001. Three months after the acquisition, David Welch left JDSU and founded Infinera. In 2013 David Welch was recognized with the JJ Thomson Medal for Electronics for his "role as pioneer in the field of optical devices and optical networks."(The Institution of Engineering and Technology, 2013) This story of star inventor and Infinera founder and President, David Welch, leaving after a change in firm leadership and taking colleagues with him matches past literature on firm disagreements and the founding of new firms (Klepper and Sleeper, 2005; Klepper and Thompson, 2010).

Our interviews with inventors offer insights into how Infinera made it's subsequent inventor hires from the offshoring firms: The founders at Infinera had significant ties, including long-time friendships, within the industry. The combination of the telecommunications bubble bursting followed by massive industry offshoring made it a good time to scoop up talent across a broad range of skills (beyond monolithic integration alone] necessary for their business. Infinera founder David Welch explains,

"What was beautiful about this time in the cycle was that all the big companies were laying people off. You could hire anybody you wanted. So we went down the list and said, “Okay. Who's good at semiconductor lasers? Who's good at indium phosphide crystal growth? Who's good at ASIC design? Who's good at optical packaging?" We made the list of who the best companies were. We identified who the critical people within each of those companies. We literally had a matrix that we developed our gene pool from. We went out and we tried to hire these people.

We got exceptional people. One of our classic stories is a guy, Chuck Joyner, he was at AT\&T, Bell Labs or, I guess at that time Lucent. They were putting on an early retirement incentive. So we interviewed chuck. It was something. From the time we first talked to him to the time he had bought a house and moved to California was, like, twenty days. We were able to go off and, Radha Nagarajan, Chuck Joyner, Andrew Dentai.... We were just able to hire the best of the best from many different disciplines." (Welch, 2011)

An inventor hired by Infinera shares his own experience at the time,

"[My former company] closed a lot of locations... required all of us to move ...to [different city]. At that time I'm already married, have daughter, ...don't want to move.... my friend from [grad school]... told me there's [a position in my area of expertise]... [at the] startup [my friend had founded, Infinera]. I 
thought okay, it's a very good opportunity,... I want to do it" (Interviewee 1. Interview by author on July $\left.8^{\text {th }}, 2013\right)$

That Infinera did not hire from the offshoring firms more inventors with expertise in the emerging technology, however, seems surprising given the potential of inventors to bring technological expertise from previous firms into new ones (Rosenkopf and Almeida, 2003; Song et al., 2003). Past literature also suggests that once an inventor has been in a particular technical area for more than three years, he or she often seeks to continue innovation activities in the same direction despite institutional changes, or other outside forces (Furman et al., 2012; Garud and Rappa, 1995). Infinera is headquartered in California - a state that does not enforce non-competes, so non-competes is not a good explanation (Marx, 2009, 2011; Marx and Fleming, 2011; Marx et al., 2010; Marx et al., 2009). Infinera does have subsidaries in Maryland and Pennsylvania, states that may more strictly enforce non-compete agreements. Yet, all of the inventors Infinera gains from companies outside California are through legal agreements (one an undisclosed agreement involving the takeover of another company's business line including licensing of patents and transfer employees, and one a formal acquisition), so again non-competes are not a good explanation. One possible explanation for why more inventors don't continue activities in the emerging technology after the burst of the bubble may be that firms' reputation for toughness in patent protection can limit knowledge flows (Agarwal et al., 2009). In such a case, inventors with expertise in monolithic integration might be responding to post-employment restraints by taking “occupational detours"(Marx, 2009), and temporarily avoiding work in the emerging technology - whether they stay within telecommunications or leave for other industries. Notably, however, with Infinera the only onshore optoelectronics component firm for telecommunications aggressively pursuing monolithic integration, the emerging technology inventors who leave the offshoring firms may be rather limited in their employment options. Thus, emerging technology inventors may also stop working in monolithic integration because they are not able to find a job in that technical area (whether due to not being offered a position at Infinera - due to insufficient qualifications or simply because Infinera didn't need more monolithic inventors, due to being unwilling to relocate to where Infinera is located, or due to not finding a suitable job in monolithic integration outside of the industry.)

Leading inventors in monolithic integration who don't end up continuing activities in the emerging technology shed insights into the challenges they faced:

"These days... you cannot find the research-type job. There are very, very, very few. It's not like the old days that companies spend a lot of money on research. It's more... development engineering." (Interviewee 2 . Interview by author on July $12^{\text {th }}, 2013$ )

"It was a tough time in the job market and so I was just happy to find a job. I... [joined] the yield group [in a computing company]...finding defects in the chips as they were being manufactured and 
finding ways to prevent defects... it was my first non-optical-electronics job." (Interviewee 3. Interview by author on March $10^{\text {th }}, 2014$ )

For some, not changing locations, due to family or otherwise, is a primary concern:

“... at that point in time solar was looking pretty attractive. To keep my family in [Area]... I decided to take the job [outside the optoelectronics industry]. ." (Interviewee 4. Interview by author on February $27^{\text {th }}, 2014$ )

[After the company the inventor was at was acquired by Infinera] “...they [Infinera] offer some positions in the headquarters but nobody took it... families are here right,... and the positions they were offering are not related to what we did before.” (Interviewee 5 . Interview by author on October $14^{\text {th }}, 2013$ )

[After the company the inventor was at was acquired by Infinera] “... I was confronted with a decision... to stay with Infinera and move to Silicon Valley or not to do that, and I ended up choosing to stay here.... This [local] company wanted to gear up to produce the device... [they] had been making. So since I had some experience in taking things from research into production, they brought me on to do that... in medical diagnostic imaging or sensing. ." (Interviewee 6 . Interview by author on March $11^{\text {th }}$, 2014)

Notably, as shown in Table 8, a few emerging technology inventors with more personal flexibility do find opportunities to leave the industry and telecommunications and continue in the emerging technology. One young inventor explains,

"Well JPL [the Jet Propulsion Laboratory at California Institute of Technology, to which the inventor goes], it offered the opportunity to do research.... the application area would be interesting, that being the space program, and the specific research environment was high quality, had good resources and it looked like I'd have a fair amount of flexibility in choosing interesting projects." (Interviewee 7. Interview by author on Dec $5^{\text {th }}, 2013$ )

\section{Discussion and Conclusion}

This paper leverages a case of extensive industry offshoring to shed new insights into the role of firms versus individuals in driving technology directions, and the constraints that can face individuals during industrial shifts. Building on past research on industry evolution and the product cycle, we explore whether (1) due to different offshore production economics, firms who move manufacturing offshore slow U.S.-based R\&D activities in an emerging technology and (2) the inventors originally within these offshoring firms, leave, and continue innovating in the emerging technology at different institutions.

Our focus is offshoring in small and medium sized optoelectronic component manufacturers for the telecommunications industry after the burst of the telecommunications bubble. We study three competing technologies in the industry that are perfect substitutes at the time of offshoring, but have performance attributes of different value to markets in the medium to long term: The emerging technology 
dramatically reduces device size, enabling optoelectronics' benefits (compared to pure electronics) to be applied in larger markets outside of telecommunications such as computing, biotechnology, energy, and military applications. The intermediate and prevailing technologies both have greater labor and assembly requirements, and lack the benefits (small size) of the emerging technology for accessing larger markets.

We find that moving all manufacturing offshore (both assembly and fabrication) is associated with a decrease in innovation in the emerging technology. These results match the economics found in Fuchs and Kirchain (2010), which show that manufacturing overseas reduces the economic viability of producing emerging technologies. These results, however, go a step farther, showing that the firms not only lose incentives for producing the emerging technology - they also reduce their innovation activities back home in that same technology. Notably, the statistically significant relationship between offshoring and reducing innovation in the emerging technology is only found once firms move fabrication capabilities offshore - the manufacturing capability key to producing the emerging technology, and that demands an intimate relationship between $R \& D$ workers and the manufacturing line. Our findings on the relationship between offshoring and innovation in technologies other than the emerging technology are equally interesting. While the offshoring of only assembly is not associated with a change in innovation in the emerging technology, it can be associated with an increase in other innovation (here, our intermediate technology and additional technologies other than the emerging one).

The above results contribute an important distinction to current debates on the relationship between manufacturing and innovation. They point out that, alone, moving manufacturing overseas may not be harmful to all innovation. What type of manufacturing is moved overseas is critical to whether - as traditional economics would suggest (Baily and Farrell, 2004; Bardhan and Jaffee, 2005) - offshoring manufacturing is associated with increased activities in higher-value activities by the offshoring firms back in the home country; or - as knowledge-based theories (Carlile, 2004; Teece, 1977; Tyre and Von Hippel, 1997) and recent work from engineering (Fuchs et al., 2011; Fuchs and Kirchain, 2010) would suggest - offshoring manufacturing to a developing country is associated with reduced innovation. What type of innovation is affected is likewise critical: offshoring can be associated with increased innovation in other areas, in no case do we find offshoring associated with increased innovation in the emerging technology. The decrease in innovation in the emerging technology associated with moving fabrication overseas may be representative, more broadly, of early-stage process-based industries (such as chemicals, pharmaceuticals, and also the early years of electronic semiconductors), as it is here, that history has repeatedly found a tight link between R\&D and manufacturing (Fuchs and Kirchain, 2010; Holbrook et al., 2000; Lécuyer, 2006; Pisano, 1997).

The opportunity to offshore at a stage in the product life cycle when there are competing product technologies may shift the timing and direction of technological activities in the firms that offshore. In 
contrast to Vernon, who imagines a shift overseas after a product is standardized and focus has shifted to process innovation (Vernon, 1966), here, the shift overseas changes the relative profitability of two competing designs mid-stream during the competition: Offshoring is associated with a slowing of the emerging, and potentially disruptive technology (Christensen, 1997) and potentially extending the life of the incumbent technology during the product life cycle (Foster, 1986; Henderson et al., 1995; Rosenberg, 1976) . Similar to Christensen's depiction of disruptive technologies (Christensen, 1997), the performance advantages (in particular, smaller size) of monolithic integration are not valued by the optoelectronic component manufacturers' existing customers in telecommunications as much as they are likely to be valued in other, larger markets (computing, sensing, biotechnology) in the longer term.

At the inventor level, contrary to past research showing the persistence of inventors in their technical fields (Furman et al., 2012; Garud and Rappa, 1995; Klepper and Thompson, 2010), we find that the majority of inventors with strong patenting records in the emerging technology depart to firms outside the industry and stop work in the emerging technology. An important minority of inventors at the offshoring firms depart to a new onshore firm, which (gaining from the offshoring firms' losses) subsequently dominates innovation in the emerging technology among optoelectronic component manufacturers for telecommunications. Surprisingly, the vast majority of the inventors who go to the onshore firm and innovate there in the emerging technology are not those with experience at the offshoring firms in the emerging technology. Given that the onshore firm does not face a climate with strict non-compete regulation, other unobservable institutional factors - such as firms' reputation for toughness in patent protection (Agarwal et al., 2009) or individual mobility constraints due to family or other personal reasons may be driving this result and thereby possibly limiting knowledge flows through mobility. Our qualitative results also suggest that with only one optoelectronics component firm for telecommunications staying onshore and aggressively pursuing monolithic integration, emerging technology inventors may in large part stop working in the emerging technology simply because suitable (and in many cases local) opportunities to do so no longer exist post-offshoring.

Our results offer new insights into the location of knowledge in firms versus individuals and the roles each play as drivers of technology trajectories. A significant literature has emphasized the role of scientist and engineer mobility in disseminating knowledge (Agarwal et al., 2004; Almeida and Kogut, 1999; Arrow, 1962; Klepper and Sleeper, 2005) and influencing technology directions (Furman et al., 2012; Garud and Rappa, 1995; Klepper and Thompson, 2010). At the same time, other literature has focused on the role of firm strategy in identifying technology trajectories and driving innovation (Abernathy and Clark, 1985; Christensen, 1997; Henderson and Clark, 1990). In this research, we find that the majority of emerging technology inventors change research directions in association with their choice of institutions (in this case, to which firms, they go). Whether this outcome is a negative one for stocks of 
human capital is hard to judge from this paper alone. The firms and their associated strategies (both in offshoring and in hiring) dominate our story on innovation. The optoelectronic component manufacturers' case suggests a strong role for firms and firm strategy in driving innovation directions, and in constraining the corresponding opportunities faced by individuals. Individual agency remains for an inventor in choosing the firms and institutions to which to move - and in the case of a very select minority, the firms they found.

\section{References}

Abernathy, W.J., Clark, K.B., 1985. Innovation: Mapping the winds of creative destruction. Research policy 14, 3-22.

Abernathy, W.J., Utterback, J.M., 1978. Patterns of industrial innovation. Journal Title: Technology review. Ariel 64, 254.228.

Agarwal, R., Audretsch, D.B., 1999. The two views of small firms in industry dynamics: a reconciliation. Economics Letters 62, 245-251.

Agarwal, R., Echambadi, R., Franco, A.M., Sarkar, M., 2004. Knowledge transfer through inheritance: Spin-out generation, development, and survival. The Academy of Management Journal, 501-522.

Agarwal, R., Ganco, M., Ziedonis, R.H., 2009. Reputations for toughness in patent enforcement: implications for knowledge spillovers via inventor mobility. Strategic Management Journal 30, 13491374.

Agarwal, R., Gort, M., 1996. The evolution of markets and entry, exit and survival of firms. The Review of Economics and Statistics, 489-498.

Agrawal, V., Farrell, D., 2003. Who wins in offshoring. McKinsey Quarterly, 36-53.

Aldrich, H.E., Pfeffer, J., 1976. Environments of organizations. Annual review of sociology, 79-105. Almeida, P., Kogut, B., 1999. Localization of knowledge and the mobility of engineers in regional networks. Management Science 45, 905-917.

Anderson, P., Tushman, M.L., 1990. Technological discontinuities and dominant designs: A cyclical model of technological change. Administrative Science Quarterly, 604-633.

Anton, J.J., Yao, D.A., 1995. Start-ups, spin-offs, and internal projects. Journal of Law, Economics, \& Organization, 362-378.

Antras, P., 2005. Incomplete contracts and the product cycle. The American Economic Review 95, 10541073.

Arora, A., Fosfuri, A., Gambardella, A., 2001. Markets for technology: The economics of innovation and corporate strategy. MIT press.

Arrow, K., 1962. Economic welfare and the allocation of resources for invention. Nber.

Baily, M., Farrell, D., 2004. Exploding the myths of offshoring. The McKinsey Quarterly.

Baldwin, C.Y., Clark, K.B., 2000. Design rules: The power of modularity. MIT press.

Bardhan, A., Jaffee, D., 2005. Innovation, R\&D and offshoring.

Bassett, R.K., 2002. To the digital age: Research labs, start-up companies, and the rise of MOS technology. JHU Press.

Bayus, B.L., Agarwal, R., 2007. The role of pre-entry experience, entry timing, and product technology strategies in explaining firm survival. Management Science 53, 1887-1902.

Berman, S.L., Down, J., Hill, C.W., 2002. Tacit knowledge as a source of competitive advantage in the National Basketball Association. Academy of Management Journal 45, 13-31.

Bessen, J., 2009. NBER PDP Project User Documentation: Matching Patent Data to Compustat Firms. Version: Beta, May.

Braum, E., MacDonald, S., 1978. Revolution in miniature. Cambridge University Press, Cambridge, UK. 
Bresnahan, T., Trajtenberg, M., 1995a. General purpose technologies: "Engines of Growth?". Journal of Econometrics 65, 83-108.

Bresnahan, T.F., Trajtenberg, M., 1995b. General purpose technologies 'Engines of growth'? Journal of Econometrics 65, 83-108.

Brown, C., Medoff, J.L., 2003. Firm age and wages. Journal of Labor Economics 21, 677-697.

Campbell, B.A., Ganco, M., Franco, A.M., Agarwal, R., 2012. Who leaves, where to, and why worry?

employee mobility, entrepreneurship and effects on source firm performance. Strategic Management

Journal 33, 65-87.

Carlile, P.R., 2004. Transferring, translating, and transforming: An integrative framework for managing

knowledge across boundaries. Organization Science, 555-568.

Carnahan, S., Agarwal, R., Campbell, B.A., 2012. Heterogeneity in turnover: The effect of relative compensation dispersion of firms on the mobility and entrepreneurship of extreme performers. Strategic Management Journal 33, 1411-1430.

Carnahan, S., Somaya, D., 2011. Competing Over Who Your Customers Hire: The Other Talent War.

Christensen, C.M., 1993. The rigid disk drive industry: a history of commercial and technological

turbulence. Business history review 67, 531-588.

Christensen, C.M., 1997. The innovator's dilemma: when new technologies cause great firms to fail.

Harvard Business Press.

Cohen, J.M., Smith, D.L., Cotter, C., Ward, A., Yamey, G., Sabot, O.J., Moonen, B., 2012. Malaria

resurgence: a systematic review and assessment of its causes. Malar J 11, 122.

Cohen, S.S., Zysman, J., 1987. Manufacturing matters: the myth of the post-industrial economy. Basic

Books New York.

Corredoira, R.A., Rosenkopf, L., 2010. Should auld acquaintance be forgot? The reverse transfer of

knowledge through mobility ties. Strategic Management Journal 31, 159-181.

Cummings, J.N., Espinosa, J.A., Pickering, C.K., 2009. Crossing spatial and temporal boundaries in

globally distributed projects: A relational model of coordination delay. Information Systems Research 20, 420-439.

Dokko, G., Rosenkopf, L., 2010. Social capital for hire? Mobility of technical professionals and firm influence in wireless standards committees. Organization Science 21, 677-695.

Dosi, G., 1982. Technological paradigms and technological trajectories:: A suggested interpretation of the determinants and directions of technical change. Research policy 11, 147-162.

Eisenhardt, K., 1989. Building theories from case study research. Academy of management review 14, 532-550.

Ettlie, J.E., 1997. Quality, technology, and global manufacturing. Production and Operations

Management 6, 150-166.

Fernandez-Mateo, I., 2009. Cumulative Gender Disadvantage in Contract Employment1. American

Journal of Sociology 114, 871-923.

Fifarek, B., Veloso, F., 2010. Offshoring and the global geography of innovation. Journal of Economic

Geography.

Fifarek, B., Veloso, F., Davidson, C., 2008. Offshoring technology innovation: A case study of rare-earth technology. Journal of Operations Management 26, 222-238.

Fleming, L., King, C., Juda, A., 2007. Small worlds and innovation. Organization Science 18, 938-954.

Foster, R.N., 1986. Innovation: The attacker's advantage. Summit Books New York.

Franco, A.M., Filson, D., 2006. Spin-Outs: Knowledge Diffusion through Employee Mobility. The

RAND Journal of Economics 37, 841-860.

Fuchs, E.R.H., Field, F.R., Roth, R., Kirchain, R.E., 2011. Plastic cars in China? The significance of production location over markets for technology competitiveness in the United States versus the People's Republic of China. International Journal of Production Economics.

Fuchs, E.R.H., Kirchain, R., 2010. Design for location? The impact of manufacturing offshore on technology competitiveness in the optoelectronics industry. Management Science 56, 2323. 
Furman, J.L., Murray, F., Stern, S., 2012. Growing Stem Cells: The Impact of Federal Funding Policy on the US Scientific Frontier. Journal of Policy Analysis and Management 31, 661-705.

Ganco, M., Ziedonis, R.H., Agarwal, R., 2014. More stars stay, but the brightest ones still leave: Job hopping in the shadow of patent enforcement. Strategic Management Journal.

Gardiner, J., 1986. Design trajectories for airplanes and automobiles during the past fifty years. Design, Innovation and Long Cycles in Economic Development, Francis Printer, London, 121-141.

Garmaise, M.J., 2011. Ties That Truly Bind: Non-Competition Agreements, Executive Compensation, and Firm Investment. Journal of Law, Economics, \& Organization 27, 376.

Garud, R., Rappa, M., 1995. On the persistence of researchers in technological development. Industrial and Corporate Change 4, 531.

Gibson, C.B., Gibbs, J.L., 2006. Unpacking the concept of virtuality: The effects of geographic dispersion, electronic dependence, dynamic structure, and national diversity on team innovation. Administrative Science Quarterly 51, 451-495.

Glaser, B.G., Strauss, A.L., 1967. The discovery of grounded theory: Strategies for qualitative research. Aldine Transaction.

Hall, B., Jaffe, A., Trajtenberg, M., 2001. The NBER patent citation data file: Lessons, insights and methodological tools, NBER working paper series.

Henderson, R.M., Clark, K.B., 1990. Architectural innovation: The reconfiguration of existing product technologies and the failure of established firms. Administrative Science Quarterly, 9-30.

Henderson, V., Kuncoro, A., Turner, M., 1995. Industrial Development in Cities. Journal of political economy, 1067-1090.

Hitt, M.A., Biermant, L., Shimizu, K., Kochhar, R., 2001. Direct and moderating effects of human capital on strategy and performance in professional service firms: A resource-based perspective. Academy of Management Journal 44, 13-28.

Holbrook, D., Cohen, W.M., Hounshell, D.A., Klepper, S., 2000. The nature, sources, and consequences of firm differences in the early history of the semiconductor industry.

Holden, H., 2003. The developing technologies of integrated optical waveguides in printed circuits. Circuit World 29, 42-50.

Hounshell, D.A., 1988. Science and Corporate Strategy: Du Pont R and D, 1902-1980. Cambridge University Press.

Kellogg, D.L., Smith, M.A., 2009. Student-to-Student Interaction Revisited: A Case Study of Working Adult Business Students in Online Courses*. Decision Sciences Journal of Innovative Education 7, 433456.

Klepper, S., 1996. Entry, exit, growth, and innovation over the product life cycle. The American Economic Review, 562-583.

Klepper, S., 2002. The capabilities of new firms and the evolution of the US automobile industry. Industrial and Corporate Change 11, 645-666.

Klepper, S., Simons, K.L., 2000. Dominance by birthright: entry of prior radio producers and competitive ramifications in the US television receiver industry. Strategic Management Journal 21, 997-1016.

Klepper, S., Simons, K.L., 2005. Industry shakeouts and technological change. International Journal of Industrial Organization 23, 23-43.

Klepper, S., Sleeper, S., 2005. Entry by spinoffs. Management Science 51, 1291-1306.

Klepper, S., Thompson, P., 2006. Submarkets and the evolution of market structure. The RAND Journal of Economics 37, 861-886.

Klepper, S., Thompson, P., 2010. Disagreements and intra-industry spinoffs. International Journal of Industrial Organization 28, 526-538.

Lécuyer, C., 2006. Making Silicon Valley: Innovation and the growth of high tech, 1930-1970. The MIT

Press.

Lepak, D.P., Snell, S.A., 1999. The human resource architecture: Toward a theory of human capital allocation and development. Academy of management review 24, 31-48. 
Li, G.-C., Lai, R., D’Amour, A., Doolin, D.M., Sun, Y., Torvik, V.I., Yu, A.Z., Fleming, L., 2014. Disambiguation and co-authorship networks of the US patent inventor database (1975-2010). Research policy 43, 941-955.

Lourdes Sosa, M., 2013. Decoupling market incumbency from organizational prehistory: Locating the real sources of competitive advantage in R\&D for radical innovation. Strategic Management Journal 34, 245-255.

Marshall, A., 1890. Principles of economics, 8th ed. Macmillan and Co., Ltd., London.

Marx, M., 2009. Good Work If You Can Get It... Again: Non-Compete Agreements, Occupational

Detours, and Attainment. Again: Non-Compete Agreements, Occupational Detours, and Attainment (August 17, 2009).

Marx, M., 2011. The Firm Strikes Back Non-compete Agreements and the Mobility of Technical

Professionals. American Sociological Review 76, 695-712.

Marx, M., Fleming, L., 2011. Non-compete Agreements: Barriers to Entry... and Exit?, Innovation Policy and the Economy, Volume 12. University of Chicago Press, pp. 39-64.

Marx, M., Singh, J., Fleming, L., 2010. Regional Disadvantage? Non-Compete Agreements and Brain Drain. INSEAD, Singapore, September 22.

Marx, M., Strumsky, D., Fleming, L., 2009. Mobility, skills, and the Michigan non-compete experiment. Management Science 55, 875.

Mickelson, A., Basavanhally, N., Lee, Y., 1997. Optoelectronic packaging. Wiley New York.

Mowery, D., Rosenberg, N., 1979. The influence of market demand upon innovation: a critical review of some recent empirical studies. Research policy 8, 102-153.

Mueller, D.C., Tilton, J.E., 1969. Research and development costs as a barrier to entry. The Canadian Journal of Economics/Revue Canadienne d'Economique 2, 570-579.

Mullor-Sebastian, A., 1983. The product life cycle theory: Empirical evidence. Journal of International Business Studies, 95-105.

OIDA, 2005. Optical Interconnects: "Thinking Inside of the Box". Optoelectronic Industry Development Association.

OIDA, 2006. Global Optoelectronics Industry Market Report and Forecast. Optoelectronics Industry Development Assoication.

Ouimet, P., Zarutskie, R., 2011. Who Works for Startups? The Relation between Firm Age, Employee Age, and Growth.

Oviatt, B.M., McDougall, P.P., 1997. Challenges for internationalization process theory: The case of international new ventures. MIR: Management International Review, 85-99.

Palomeras, N., Melero, E., 2010. Markets for inventors: learning-by-hiring as a driver of mobility. Management Science 56, 881-895.

Parrotta, P., Pozzoli, D., 2012. The effect of learning by hiring on productivity. The RAND Journal of Economics 43, 167-185.

Pfeffer, J., Leblebici, H., 1973. Executive recruitment and the development of interfirm organizations. Administrative Science Quarterly, 449-461.

Pisano, G.P., 1997. The development factory: unlocking the potential of process innovation. Harvard Business Press.

Pisano, G.P., Shih, W.C., 2009. Restoring American Competitiveness. Harvard Business Review 87, 114125.

Ricardo, D., 1891. Principles of political economy and taxation. G. Bell and sons.

Rosenberg, N., 1976. Perspectives on technology. CUP Archive.

Rosenberg, N., Trajtenberg, M., 2004. A general-purpose technology at work: The Corliss steam engine in the late-nineteenth-century United States. The Journal of Economic History 64, 61-99.

Rosenkopf, L., Almeida, P., 2003. Overcoming local search through alliances and mobility. Management Science 49, 751-766.

Rosenkopf, L., Tushman, M.L., 1998. The coevolution of community networks and technology: Lessons from the flight simulation industry. Industrial and Corporate Change 7, 311-346. 
Sahal, D., 1985. Technological guideposts and innovation avenues. Research policy 14, 61-82.

Samuelson, P.A., 2004. Where Ricardo and Mill rebut and confirm arguments of mainstream economists supporting globalization. The Journal of Economic Perspectives 18, 135-146H.

Sarkar, M., Echambadi, R., Agarwal, R., Sen, B., 2006. The effect of the innovative environment on exit of entrepreneurial firms. Strategic Management Journal 27, 519-539.

Schabel, M., 2005. Current State of the Photonics Industry. Microphotonics: Hardware for the Information Age. L. Kimerling. Cambridge, MA, MIT Microphotonics Center.

Shah, J., 2007. Ultraperformance Nanophotonic Intrachip Communications: UNIC. DARPA/MTO-

Frontiers of Extreme Computing.

Singh, J., Agrawal, A., 2011. Recruiting for Ideas: How Firms Exploit the Prior Inventions of New Hires.

Management Science 57, 129-150.

Singh, J., Marx, M., 2013. Geographic constraints on knowledge spillovers: Political borders vs. spatial proximity. Management Science 59, 2056-2078.

Somaya, D., Williamson, I.O., Lorinkova, N., 2008. Gone but not lost: The different performance impacts of employee mobility between cooperators versus competitors. Academy of Management Journal 51, 936953.

Song, J., Almeida, P., Wu, G., 2003. Learning by Hiring: When Is Mobility More Likely to Facilitate Interfirm Knowledge Transfer? Management Science 49, 351-365.

Sorensen, J.B., Stuart, T.E., 2000. Aging, obsolescence, and organizational innovation. Administrative Science Quarterly, 81-112.

Sosa, M.L., 2009. Application-specific R\&D capabilities and the advantage of incumbents: Evidence from the anticancer drug market. Management Science 55, 1409-1422.

Sosa, M.L., 2011. From Old Competence Destruction to New Competence Access: Evidence from the Comparison of Two Discontinuities in Anticancer Drug Discovery. Organization Science 22, 1500-1516. Stuart, T.E., Sorenson, O., 2003. Liquidity events and the geographic distribution of entrepreneurial activity. Administrative Science Quarterly 48, 175-201.

Szulanski, G., 1996. Exploring internal stickiness: Impediments to the transfer of best practice within the firm. Strategic Management Journal 17, 27-43.

Tassey, G., 2010. Rationales and mechanisms for revitalizing US manufacturing R\&D strategies. The Journal of Technology Transfer 35, 283-333.

Teece, D., 1977. Technology transfer by multinational firms: the resource cost of transferring technological know-how. The Economic Journal 87, 242-261.

The Institution of Engineering and Technology, 2013. IET Awards - J J Thomson Medal for Electronics. Retrieved from http://conferences.theiet.org/achievement/awards/medals/thomson.cfm.

The World Bank, 2014. World development indicators. Retrieved from http://data.worldbank.org/. Tushman, M.L., Rosenkopf, L., 1992. Organizational determinants of technological-change-toward a sociology of technological evolution. Research in organizational behavior 14, 311-347.

Tyre, M., Von Hippel, E., 1997. The situated nature of adaptive learning in organizations. Organization Science 8, 71-83.

USPTO, 2010. Overview of the U.S. Patent Classification System (USPC).

Utterback, J.M., 1996. Mastering the dynamics of innovation. Harvard Business Press.

Utterback, J.M., Kim, L., 1985. Invasion of a stable business by radical innovation, The management of productivity and technology in manufacturing. Springer, pp. 113-151.

Ventura, S., Nugent, R., Fuchs, E., 2014. Seeing the non-stars: (Some) sources of bias in past disambiguation approaches and a new public tool leveraging labeled records.

Vernon, R., 1966. International investment and international trade in the product cycle. The Quarterly Journal of Economics 80, 190-207.

Welch, D.F., 2011, March 7. Interview by Kinnane, A. Optical Society of America Oral History Project, http://www.osa.org/osaorg/media/osa.history/Transcripts/Welch,_David_Interview_(final)_2011-03.pdf. 


\section{Appendix 1: Firm Case Study}

The strong effect of individual firm strategy on patenting found in the fixed effects regression analysis argues for a case-study approach to further understand the individual strategies of each firm. In case study research, we are not limited to having the same data for each firm, and can thus leverage a broader amount and more heterogeneous sources of data in informing our conclusions. In assessing the individual firm strategies we categorize them into 5 groups: the all-onshore strategists, the all offshore strategists, the split offshore strategists, the late offshorers, and the early exiters.

\section{The All-Onshore Strategiests}

\subsection{The On-shore Integrator: Infinera}

Infinera is the top integrated patent producer ( $15 \%$ of all integrated patents in our sample, and $23 \%$ of all monolithically integrated patents in our sample) and one of the only two firms ${ }^{1}$ for whom over $50 \%$ of its patents are monolithically integrated. Infinera was founded in 2000 and stays on-shore. From figure 9 in Appendix 6, we can see Infinera started their innovation activities with almost equal efforts on integrated and non-integrated design (5 integrated vs. 6 non-integrated) in 2002. Of these 5 integrated patents, one of them is hybrid design and four monolithic. After 2003, Infinera shifts its focus to monolithically integrated designs and all its integrated patents, which are twice the number of its nonintegrated patents, are monolithic.

\subsection{The On-Shore Non-Integrators: LSI, Axsun, Xponent, Prima Luci}

Four firms, LSI, Axsun, Xpnent, and Prima Luci, stay entirely on-shore; however, different from Infinera, their patenting is focused on non-integrated or hybrid designs. None of these firms are in the topten, by magnitude, of integrated (monolithic or hybrid or both) patentors. Future work should more carefully explore exactly what optoelectronic components these firms make for the telecommunication market, and how they compete.

\section{The All-Offshore Strategists}

Opposite to the firms that keep all production in the U.S., another set of firms move all production overseas. These firms include Finisar, Agilent (Avago), Agere, Oplink, AFOP. Finisar moved assembly manufacturing first and then fabrication manufacturing offshore. The other firms moved assembly and fabrication offshore in the same year.

\subsection{The Incremental Offshorer: Finisar}

Like Infinera, Finisar is one of the top integrated patent producers; however, in contrast to Infinera, Finisar focuses its integrated innovations on hybrid designs ${ }^{2}$. Finisar is also the second-highest non-

\footnotetext{
${ }^{1}$ Another is NeoPhotonics. NeoPhotonics has half of its patents integrated and half non-integrated. All of the integrated patents are monolithic. It moved offshore in 2005 and seems to shift their focus to non-integrated design, which we need more data after 2005 to prove.

${ }^{2}$ Four percent (20) of Finisar's total patents (507) are integrated and $70 \%$ of its integrated patents are hybrid.
} 
integrated patent producer among our focus firms. There is an interesting relationship between Finisar's innovation activities and its manufacturing locations. After the telecom bubble (2000), Finisar started to go offshore in 2001. It first moved only its assembly manufacturing followed by fabrication manufacturing in 2003. Prior to moving its fabrication offshore, Finisar kept increasing its non-integrated patents and working on both monolithic and hybrid designs ${ }^{3}$. After 2003, Finisar decreases its nonintegrated patenting and reduce its monolithic productivity; during the same time, however, its ratio of hybrid patents to total optoelectronic patent (monolithic, hybrid and non-integrated) increases. ${ }^{4}$

\subsection{The All-At-Once Offshorers: Agilent(Avago), Agere, Oplink, AFOP}

Several firms (Agilent (Avago) ${ }^{5}$, Agere, Oplink, AFOP) also move offshore, but, unlike Finisar, move their fabrication and assembly offshore in the same year. The first two, Agilent and Agere, have high revenues (within Top 3) ${ }^{6}$ and high non-integrated patent productivity (within Top 5). The last two, Oplink and AFOP, have lower revenues. All of them focus on non-integrated designs and if they have integrated design patents these patents, except for in the case of Agere ${ }^{7}$, focus more on hybrid technologies. In the case of Agere, $94 \%$ of its patents are in non-integration; however, within the integrated patents it has, the majority is monolithic. After Agere went offshore, it only had two integrated patents (one hybrid one monolithic) in 2003 and none in the following years. Similar to Agere, many of the other firms return to exclusively patenting in non-integrated technologies after trying briefly to do integration (in their cases largely in hybrid technologies). Overall, the earlier these firms moved offshore, the lower percentage of monolithic patents they had ${ }^{8}$.

\section{Hedging Bets - The Split Offshore Strategists}

In addition to the groups who are entirely offshore or entirely on-shore, there is another group of firms - those that keep their fabrication on-shore and move their assembly overseas. This set includes JDSU, TriQuint, Avanex and Picolight. JDSU and TriQuint have more resources (being the fourth and fifth-highest revenue earners). Avanex and Picolight compared to JDSU and TriQuint, have relatively

\footnotetext{
${ }^{3}$ Before 2003, Finisar have half of its integrated patent in hybrid technology and half in monolithic.

${ }^{4}$ Finsiar's non-integrated patents decreased from 127 to 111 to 106 to 39 (96\%, 97\%, 95\%, 91\% of its total optoelectronic patents respectively) from 2003 to 2006; its hybrid integrated patents increased from 2 to 3 to 6 to 3 (40\%, 75\%, 100\%, 75\% of its integrate patents; $2 \%, 3 \%, 6 \% 7 \%$ of its total optoelectronic patents) from 2003 to 2006; its monolithic integrated patents decreased from 3 to 1 to 0 to 1 (60\%, 25\%, $0 \%, 25 \%$ of its integrate patents; $2 \%, 1 \%, 0 \%, 2 \%$ of its total optoelectronic patents) ${ }^{5}$ We consider Agilent and Avago together because Avago was divested from Agilent in 2005. Originally, Agilent was divested from HP in 1999.

${ }^{6}$ The financial data, i.e. revenue and R\&D, in the firm case studies are all on 2005 base.

${ }^{7}$ Here, we do not consider Oplink, though the ratio of its hybrid to monolithic design is 1:1, because it only has one patent for each type of integration. The number of its integrated design is too few to observe the preference for hybrid or monolithic.

${ }^{8}$ AFOP moved offshore in 1997 and had 0\% of its patents are monolithic; Agilent(Avago) moved offshore in 1999 and the percentage is 0.9\%; Oplink moved in 2001 and the percentage is 1.1\%; Agere moved offshore in 2002 and the percentage is $4.1 \%$
} 
small revenues ${ }^{9}{ }^{10}$. Notably, Avanex merged with Bookham in 2008; Picolight is a private firm and was acquired by JDSU in 2007.

\subsection{The Rich Hedgers: JDSU, TriQuint}

JDSU and TriQuint both focus on non-integrated patents but also work on integrated design with a preference for monolithic technology. JDSU at first patented only in non-integrated designs. After 1994, it started also to patent in hybrid designs, and one year later it extended its innovation to monolithic designs. Overall, JDSU focuses most on non-integrated patents ${ }^{11}$ but by magnitude has the second highest number of integrated patents in our focus group and the third highest monolithic ( $60 \%$ of JDSU's integrated patents are monolithic) ${ }^{12}$. After JDSU move assembly offshored in 2002, the percentage of non-integrated patents decreased slightly; the percentage of hybrid design increased and that of monolithic design also increased. Then in 2005, JDSU's patenting in all areas begins to drop. TriQuint, which is smaller than JDSU $^{13}$, also mainly worked on non-integrated designs ${ }^{14}$. By pure magnitude, TriQuint is not as dominant in integrated patenting as JDSU - it has the $12^{\text {th }}$ highest number of integrated patents and $11^{\text {th }}$ highest number of monolithic patents; however, like JDSU, more than half $(57 \%)$ of TriQuint's integrated patents are monolithic. TriQuint move assembly offshore in 2001. Before 2001, TriQuint focused exclusively on non-integrated patents. Between 2001 and 2003, it started to work on both monolithic and hybrid designs; then it stopped working in integration. In the two years TriQuint had monolithic patents, its non-integrated patent numbers drop.

\subsection{The Poor Hedgers: Avanex and Picolight}

Avanex and Picolight also focus mainly on non-integrated design and when they patent in integration they have highly preference for monolithic design ${ }^{15}$. Similar to the findings from TrQuint, in the early years as Avanex and Picolight increased their monolithic patents their non-integrated patenting decreased. After Avanex went offshore in $2003^{16}$, its patent numbers dropped except the number of hybrid patents. However, Avanex's revenue rose by 4 times in 2004 and held this increasing tendency. Picolight started to patent in non-integrated in 1995 and in integrated (only monolithic) in 1998. After it went offshore in 2003 , its patent productivity in all areas decreased.

\footnotetext{
${ }^{9}$ The ratio of Avanex's revenue to JDSU's revenue is $2 \%$ to $3 \%$ from 2000 to $2003,17 \%$ and $23 \%$ in 2004 and 2005 . The ratio of Avanex's revenue to TriQuint's revenue is $6 \%$ to $55 \%$ during the 2000 s. Picolight is a private firm. Its annual revenues might be $\$ 30$ million to $\$ 50$ million, which were below 5\% of JDSU's revenue and around $11 \%$ of TriQuint's.

${ }^{10}$ Matsumoto, C., Jdsu Picks up Picolight for $\$ 115 \mathrm{~m}$, http://www.lightreading.com/document.asp?doc_id=118325, accesed on

${ }^{11} 95 \%$ of JDSU'S total patents are non-integrated.

12 JDSU founded in 1999; however, it came from a merger of two firms, JDS Fitel and Uniphase. That is why it had patents, revenue and $R \& D$ spending before the documented founded time.

${ }^{13}$ Even thought the two firms are both top 5 in revenue, JDSU earned 1.7 to 8.5 times the revenue of TriQuint each year.

${ }^{14} 88 \%$ of TriQuint's patent are non-integrated.

${ }^{15}$ Avanex has $85 \%$ of integrated patents as monolithic and Picolight has $100 \%$ of integrated patents as monolithic.

${ }^{16}$ Avanex moved assembly offshore in 2003 but it did not move active optical component until 2006.
} 


\section{The Late Offshorers: Bookham, Kotura, CyOptics, NeoPhotonics, OCP, Emcore, Opnext}

Some firms went offshore after 2005. In these cases, we lack complete patent data to show the change in their patenting after their offshoring. Bookham, Kotura, Cyoptics and NeoPhotonics went offshore in 2005; OCP moved offshore in 2006; Emcore and Opnext moved offshore in 2007. All of these late offshoring firms keep their fabrication on-shore, except NeoPhotonics. All firms in this group have the majority of their patents in non-integrated technologies, except NeoPhotonics. Among these firms, only Bookham and Neophotonics have, by magnitude, a large number of integrated patents. Here, Bookham, with the $4^{\text {th }}$ largest number of integrated patents, the $2^{\text {nd }}$ largest number of monolithic patents, and the $7^{\text {th }}$ largest number of hybrid patents is most interesting. In its integrated patenting history, Bookham at first mainly focuses on the monolithic design, but starting in 2000 its monolithic patent number gradually decrease and it starts to patent in hybrid designs. ${ }^{17}$

\section{The Early Exiters}

Within our research scope, several firms exit the market prior to 2005 (but all after the telecom bubble 2000). Some of them were acquired (SDL and Optronx by JDSU in 2001 and 2002; Lightwave by NeoPhotonics in 2003; New Focus by Bookham), and some exited without being acquired (LNL in 2004, Teraconnect in 2003). In this group, all of the firms are private, except New Focus. Among the acquired firms, SDL stays onshore and - while it has mostly non-integration patents -- its integrated patents are focused on monolithic. Lightwave also focuses on integration, with more than half of those integrated patents being monolithic. New focus is focused on non-integrated patents and moves offshore before being acquired. Future work should seek to better understand what resources (patents, offshore manufacturing capabilities, or otherwise) JDSU and Bookham were seeking in acquiring each of these firms. Both of the non-acquired exiters had lower numbers of patents than most of the other focus firms.

\section{Case Study Summary}

Our in-depth case studies of these firms depicts a landscape of firms with vastly different resources and strategies: Infinera stays onshore and dominates in the most advanced monolithically integrated technologies, while the firms that move offshore either from the start lack or move out of the most advanced monolithically integrated technologies. These findings broadly support the production economics published by Fuchs and Kirchain 2010. Perhaps most interesting, however, are the split strategists. As is suggested in Fuchs and Kirchain 2010, here the large-resource firms that take a split strategy survive while the lower-resource firms with split strategies are eventually acquired. Fuchs and Kirchain, however, suggest that this strategy may be untenable even for the large-resource firms, due to the challenges of maintaining a strategy where success in integration R\&D in the U.S. means the decline

\footnotetext{
${ }^{17}$ Kotura, Cyoptics, NeoPhotonics, and Opnext are private and they have a smaller total number of patents than most of other firms in our focus group. OCP only had 3 integrated patents; the lowest acceptable to make it into our focus firm scope.
} 
Appendix 1

of assembly needs in developing East Asia and vice versa. In our data to-date, JDSU appears to sustain both activities, although its monolithic integration activities decline in our final year of good data. In the case of TriQuint, which started with less comparative advantage in monolithic integration among our focus firms, it eventually gets out of integration patenting (monolithic and hybrid). It remains to be seen how JDSU' monolithic integration activities will fare in the long term. 


\section{Appendix 2. Patent Application Analysis}

Our analysis of the focus firms' patent data shows, on average, a one to four year gap between patent application dates and patent granting dates. As a consequence, while the majority of the firms went offshore between 1997 to 2007 (one in 1997, one in 1998, one in 2000, three in 2001, two in 2002, two in 2003, four in 2005, one in 2006 and two in 2007), currently we only are able to observe three to nine years of post-offshoring patenting behavior for seventeen firms and have no reliable post-offshoring patenting data for the seven late mover firms (moved offshore 2005-2007). In our negative binomial patent count models, these late movers are modeled then as being essentially onshore for our full observation period (1992 to 2006). In an attempt to overcome this limitation and extend our observation period, we explored using patent applications from the USPTO database, in addition to granted patents, to represent firms' innovative outcomes. Our initial hope was to include the application counts as a predictor variable (for years prior to 2006) or as a prediction for the patent counts from 2007 to 2010 (by using the ratio of observed applications to granted patents prior to 2006). Regretfully, we found many challenges when using the USPTO published applications data. First, application data is only available on the online USPTO database from March 2001 to the present. Second, firms have the right to ask the USPTO to not to publish their application. Third, if a firm does not request that the application not be published, unless they specifically request the patent application be published earlier, the application is only published after eighteen months. Fourth, if a firm's patent is granted prior to this 18-month period, even if the firm allowed the application to be published, the patent will go directly to being published as a granted patent and not show up in the application data. Given the above, we would expect the available application data to undercount the true number of patents granted (or going to be granted). Indeed, using the application data from 2001 to 2006, we found that 15 of our 28 firms have, in one or more years, a ratio of granted patents to published applications larger than one, suggesting that many of their patent applications for one reason or the other were never published. We also found that these ratios are very different by firm and by year; the firm's average six-year ratios ranges from 0 to 21.33 (standard deviation: 0.03 to 12.07$)$. To further quantify the appropriateness of using the granted patents to applications ratio to predict patent counts, we calculated the probability of observing the 2001-2006 patent counts by firm assuming a Poisson distribution with a mean vector of the firm's predicted patent counts (using the application data). We explored using ratios based on integrated and non-integrated ${ }^{1}$ patent/application counts at three different levels (firm, optoelectronic industry and the USPTO). When looking at non-integrated patents, the probability of observing the 2001-2006 counts given the firm-level ratio ranges from 0 to 0.04 ( 0 for 21 of 28 firms). The probability of observing the 2001-2006 counts given the industry-level ratio ranges from 0 to 2E-9; using the USPTO-level ratio, the probabilities range from 0 to 0.02 . Again, for these later two levels of non-integrated patent ratios, we found a ratio of 0 for 
21 of 28 firms. For monolithic patents, the probabilities for all three ratios (firm-level, industry-level, and USPTO-level) range from 0 to 1 ( 0 for 19 of 28 firms). The firms with probability one of observing their 2001-2006 counts are those who have not patented in monolithic integration. So although we may be able to predict the patent counts of a few special cases (i.e. those who have never patented in an area), in general, we are unable to successfully predict the patent counts using available application data. Moreover, the above analysis presumes that the 2001-2006 ratios might be reasonable prediction tools for patent counts pre-2006 or 2007-2010. Even within 2001-2006, we saw a wide variation in granted patent to application ratios. This wide variation might be attributable to different firm application publication strategies over time, particularly if the firms have moved offshore. Using the same ratio of granted patents to application from 2001-2006 to predict granted patents either pre-2006 or 2007-2010 in the presence of publication strategy changes could potentially be very misleading. Thus, we conclude the current available application data from the USPTO database, unfortunately, is not suitable to extend the length of our observation period. 